\title{
La vie de Mar Benjamin.
}

Texte syriaque.

Par V. Scheil.

Le texte de la vie de Mar Benjamin se trouve à la Bibliothèque patriarcale jacobite de Mardin, sur un manuscrit qui paraît être du XVII ${ }^{\text {mc }}$ siècle. J'en dois une copie à l'obligeance de Monseigneur $\mathrm{R}_{\mathrm{A}}$ ต̣MÂNI, archevèque d'Alep, assez louablement connu de tous ceux qui s'intéressent aux Lettres syriaques.

L'auteur de cette composition dût vivre au quatrième du cinquième siècle, aux temps mêmes de son héros, ou peu après. Il dit en effet avoir entendu de la bouche des compagnons du saint le récit de ses premières austérités.

Le fragment final est d'une autre main et d'une époque postérieure. Extrait de la vie de Mar Hanania, il sert d'appendice à celle de Mar Benjamin, pour expliquer comment le couvent de Mar Chlimoun où fut transporté le corps de Mar Eugène par son disciple Benjamin, ainsi qu'il est raconté au long dans sa vie, fut nommé plus tard couvent de Mar Hanania.

Il existe un autre manuscrit d'une vie de Mar Benjamin, au Musée Britannique Add. 14.733 (nº 96 I du cata-

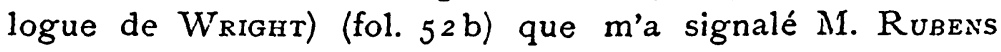
Duval et dont je dois une copie à l'obligeance de M. E. A. Wallis Budge. Les deux vies de Mar Benjamin n'en font qu'une. C'est un seul récit qu'on dirait recopié de mémoire. Avec beaucoup de variantes insignifiantes, les textes 
se suivent pas à pas. Cependant dans le récit de Londres, ont été omis l'épisode de la translation des restes de Mar Eugène, et l'appendice tiré de la vie de Mar Hanania. Ce dernier morceau d'ailleurs ne fait pas partie, à proprement parler, de la vie du saint. Le premier aura été condamné et omis par un copiste, à cause des tendances anti-nestoriennes qui s'y trahissent.

Nous donnons le texte de Mardin (A) avec les variantes de celui de Londres (B).

Mar Benjamin avait une trentaine d'années, au temps de la persécution de Julien l'Apostat. La date de 678 , assignée par le manuscrit à ce dernier évènement est légèrement inexacte, puisque cet empereur mourut en l'an 675 des Séleucides. Mar Benjamin étudia pendant vingt ans à l'école de Mar Eugène, embrassa ensuite la vie religieuse et en parcourut successivement les trois étapes, comme presque tous les grands moines de son temps.

Il fut d'abord Cénobite, vivant et travaillant en commun avec des frères, pendant vingt ans.

Puis sans quitter la Communauté, il s'isola d'elle et fut moine pendant vingt ans.

Après cette réclusion imparfaite, il se retira entièrement du monde pour devenir ermite ou anachorète. Ce fut d'abord dans le voisinage de son couvent, dans la montagne d'Fzelo, puis au Sinaï, enfin dans le désert de Scété ou Asqit en Egypte. Les solitaires d'Egypte jetaient alors un tel éclat de sainteté que de toutes les régions, on allait y chercher le secret de la perfection.

Arrivé aux sommets de la vie spirituelle, Mar Benjamin devint fondateur. Il rentra dans son pays au moment où l'hérésie de Nestorius pénétrait en Mésopotamie. Il construisit un couvent de Cénobites près de Dougan, au dessous de Mardin, et entrant pleinement dans le mouvement intellectuel national qui partait d'Edesse, il adjoignit au couvent une grande Ecole.

Il mourut le I de Tichri II, vers l'an 460. 


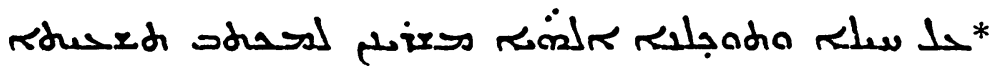

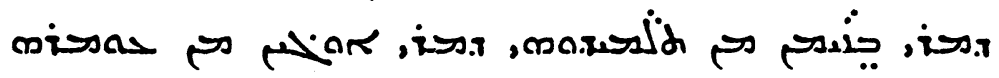
غه זים

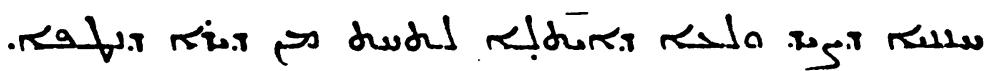

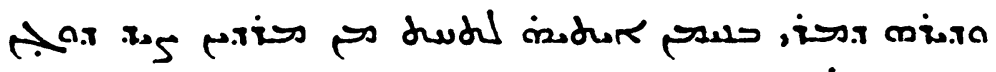
مiأ אתותה.

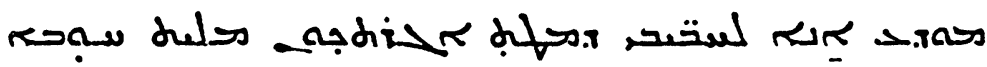

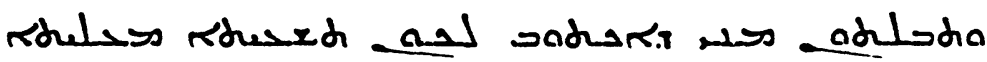
ग.

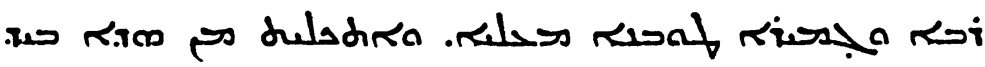

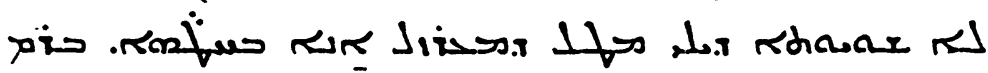

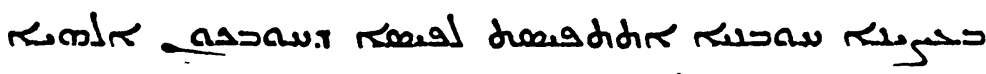

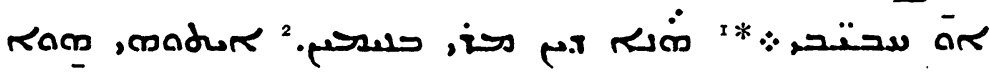
קעl

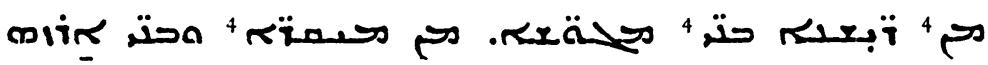

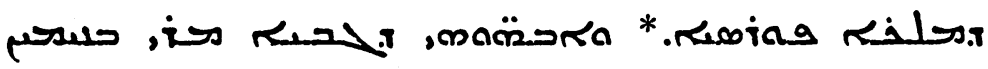
sمrsano $5 *$ *as.

I Le commencement est remplacé dans B par fus

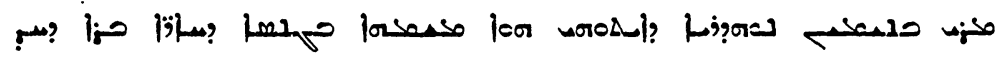

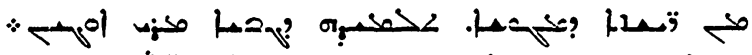

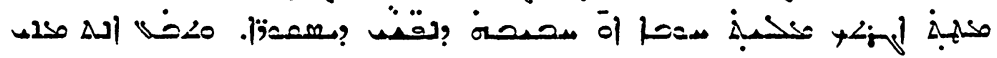
?
$2 B$ B pour 2 "
3 B $|; \angle|$ pour $\Delta=$
4 Om. B

5 B naer=l $\leftarrow$ ? 


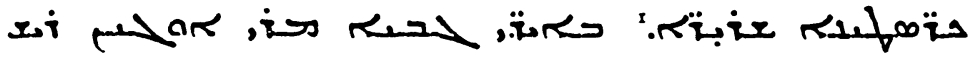
amo . rm sitar

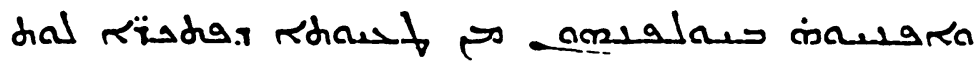

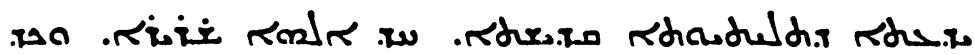

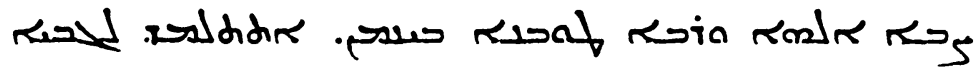
sis ת.s

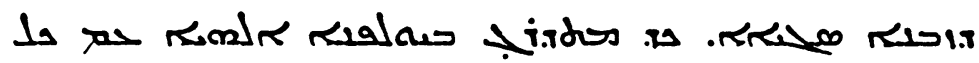

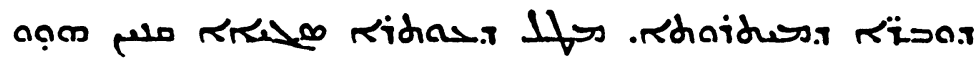

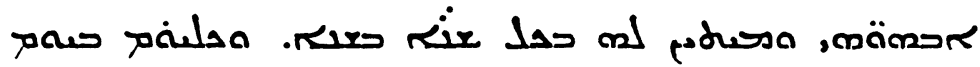
1.

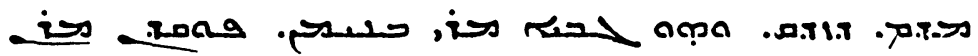

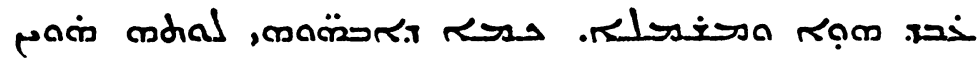

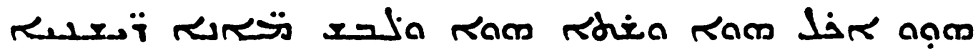

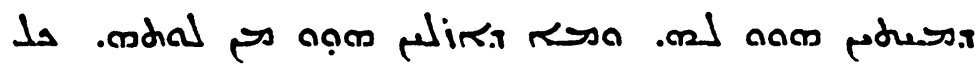

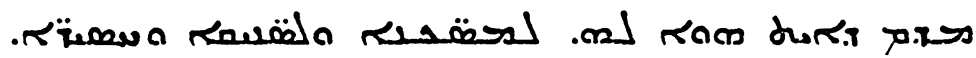
תallos ras

I Om. B

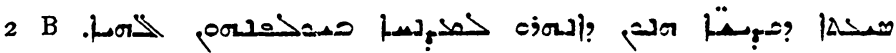

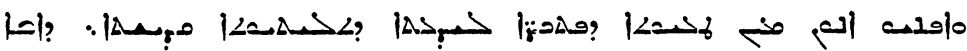

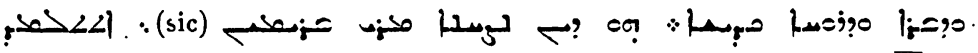
لغ Zeitschr. f. Assyriologie, XII. 
مد5 ת.

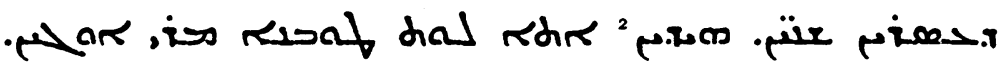
* محل.

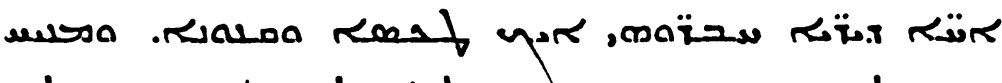

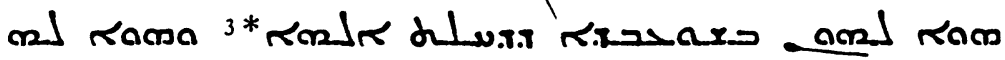
rom >sdesso. ram

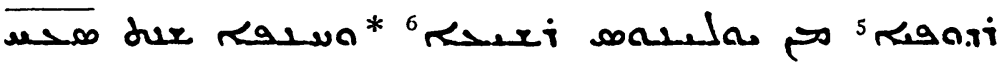

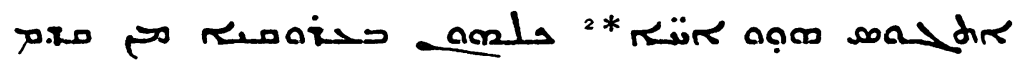

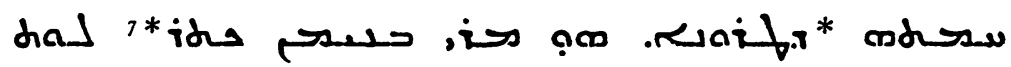

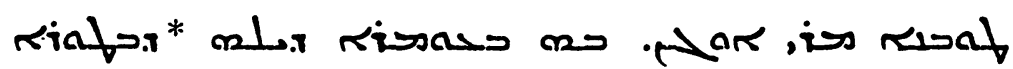

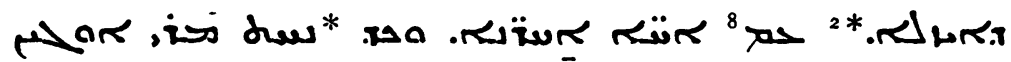

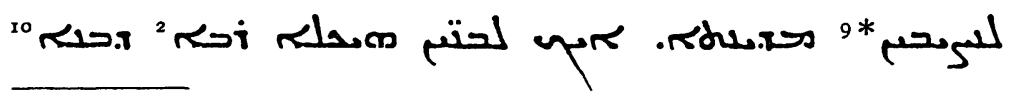

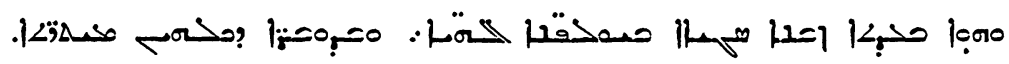

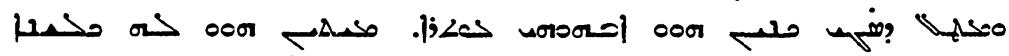

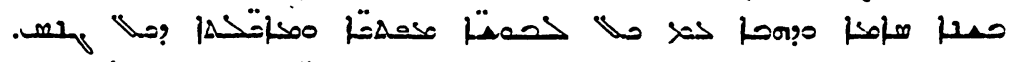

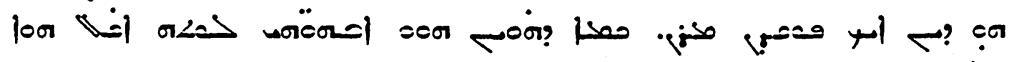

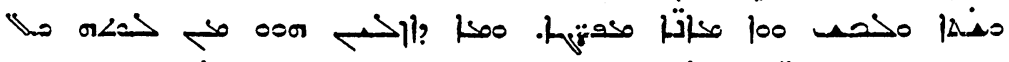

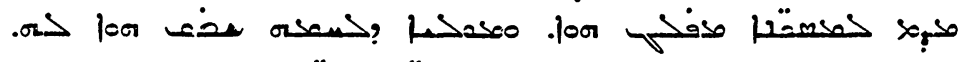
I Add. B مصحا 3 B

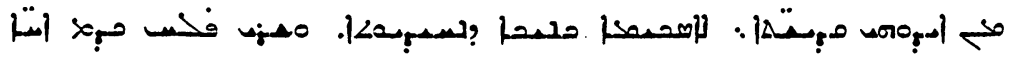
|-1 4 Add. B 50 7 B ro Add. $B$ lea 


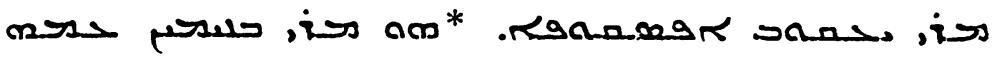
ז.

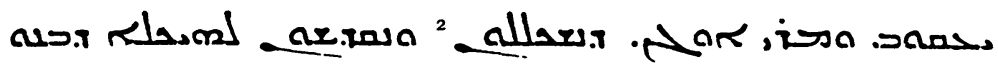
لנ

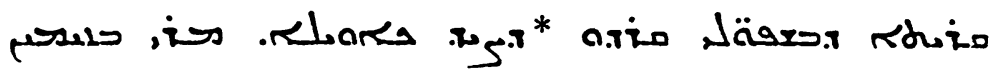

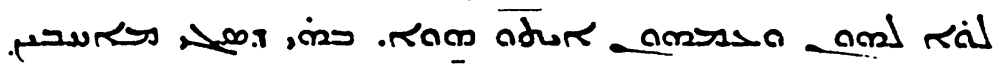

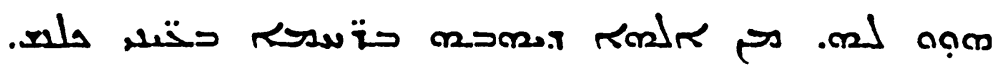

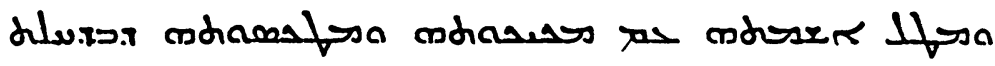

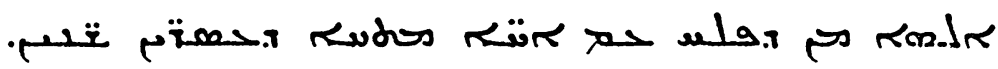

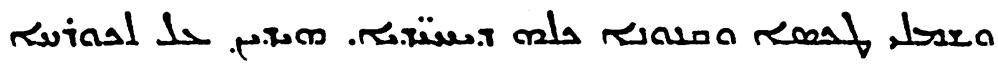

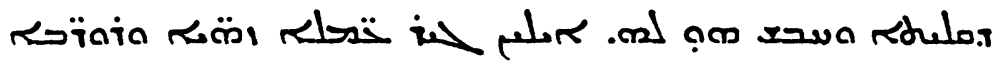

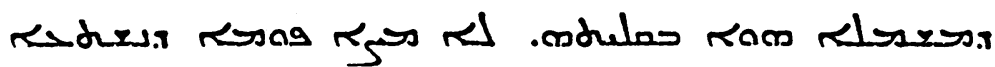

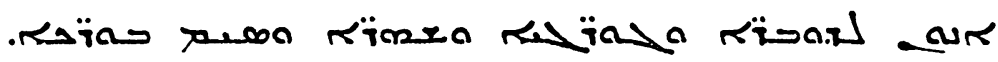

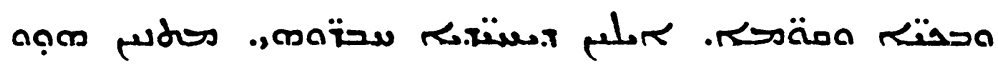
ل.

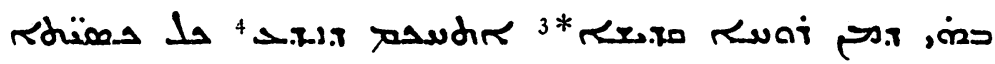

I B lor vored porss or or 2 Om. B

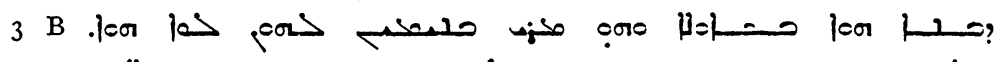

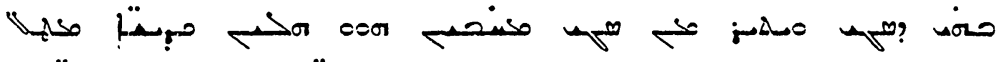

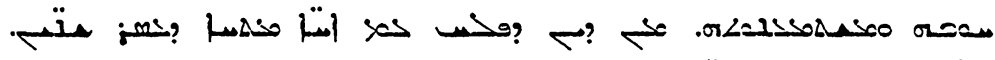

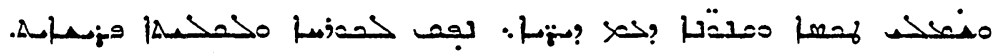

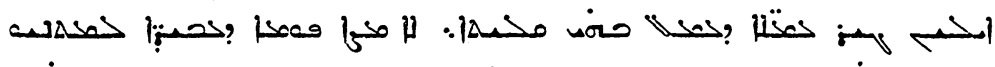

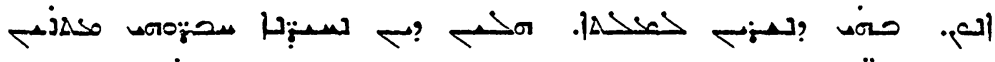
cor

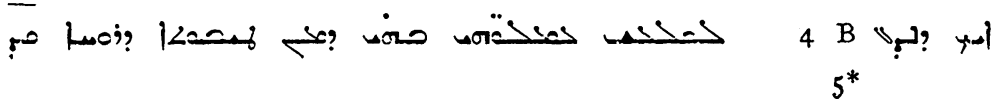




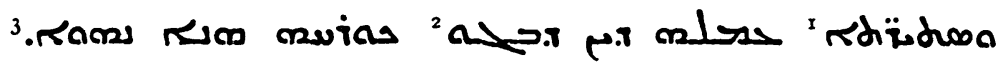

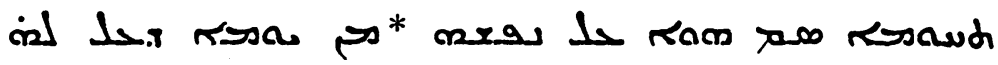

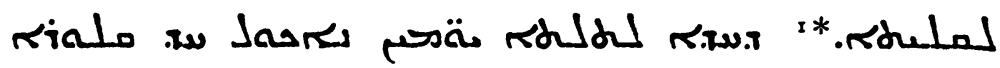

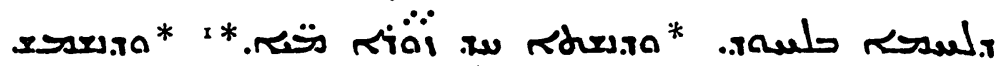

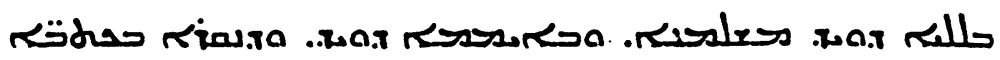

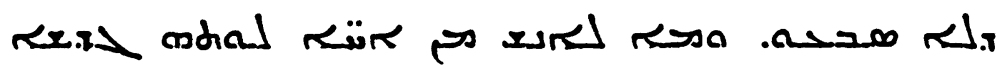

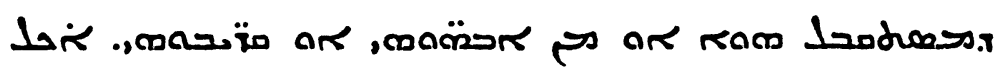

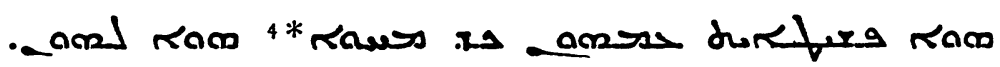

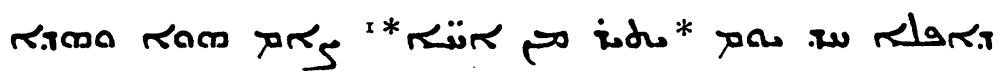

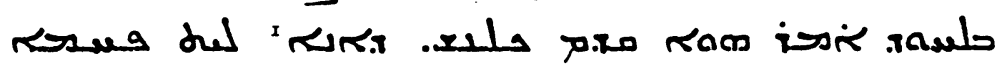

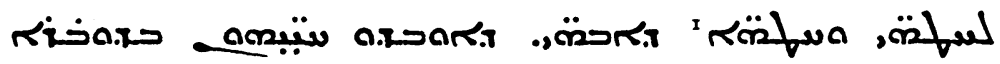

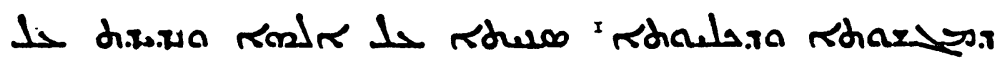

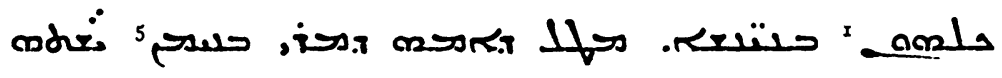

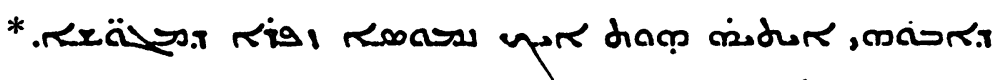

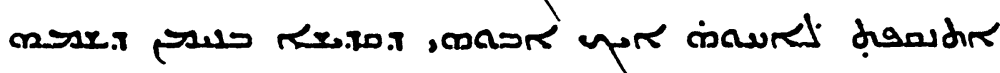

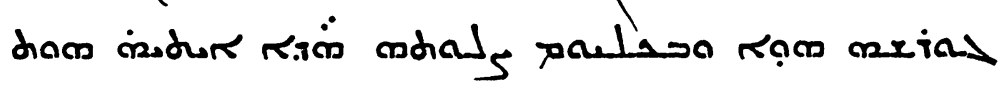
a dial mbarsh.

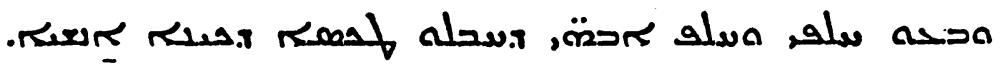

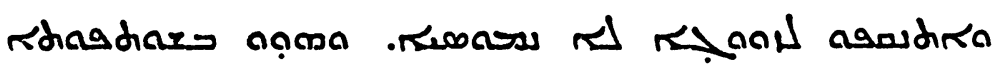

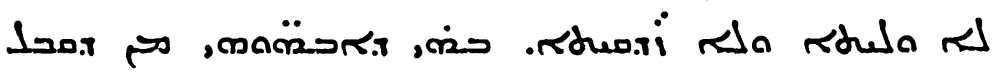

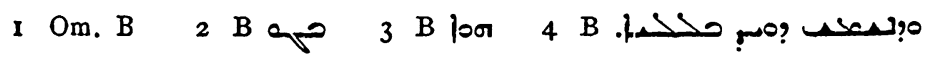

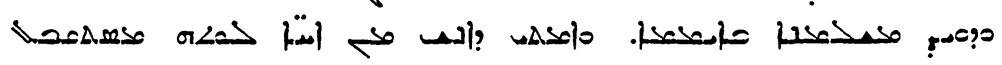

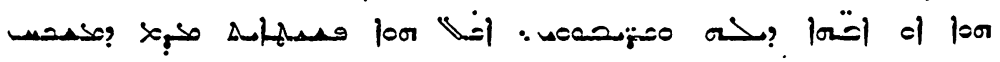

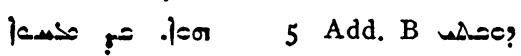




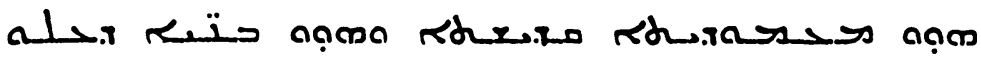

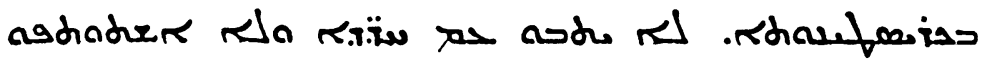

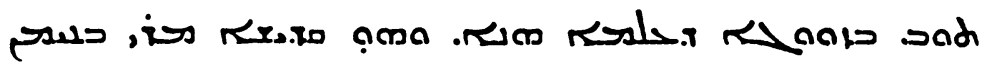

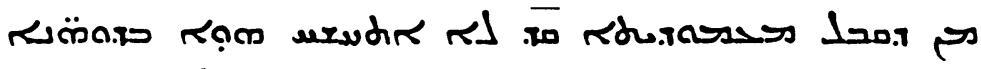

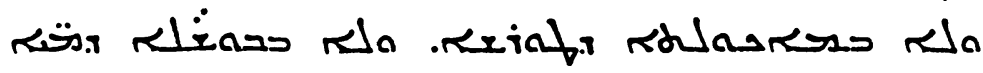

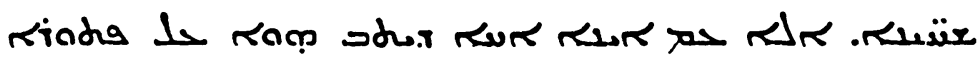
rom

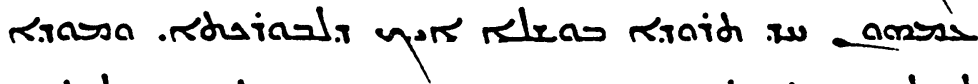
תח

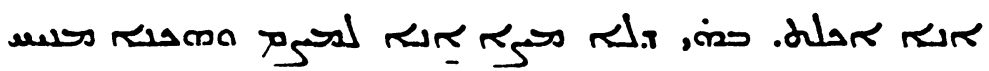

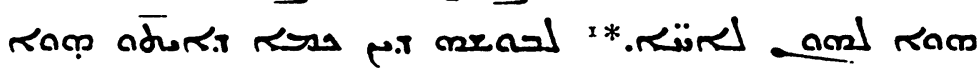

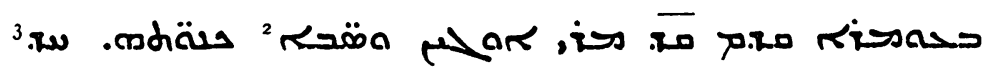

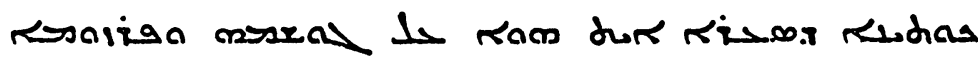

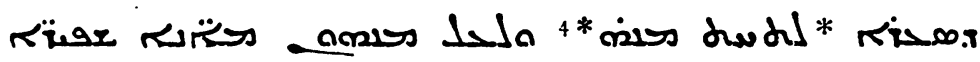

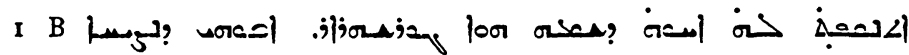

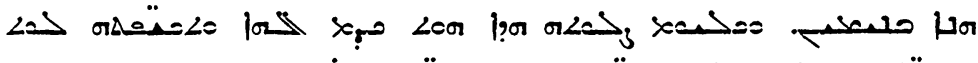

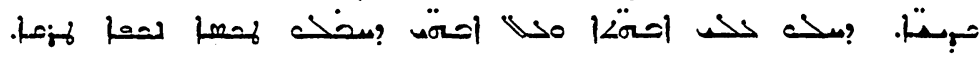
|lill

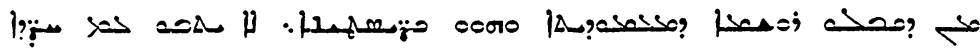

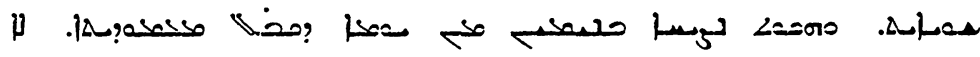

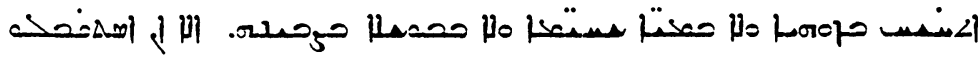

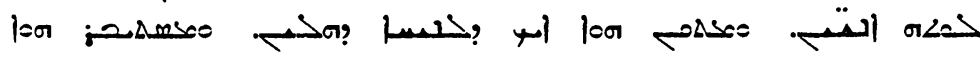

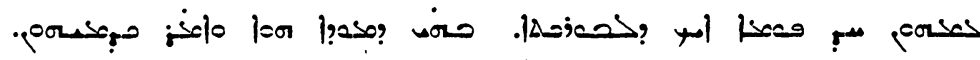
l)

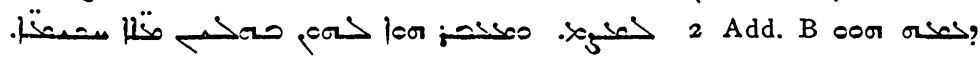
3 On. B 4 B $\sigma_{j} m \Omega$ 


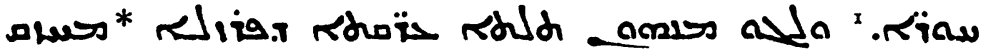

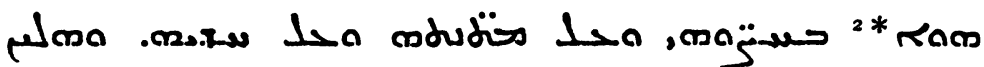

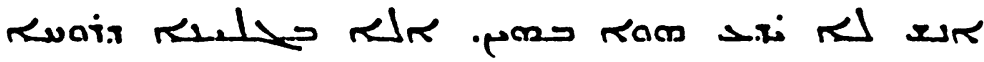

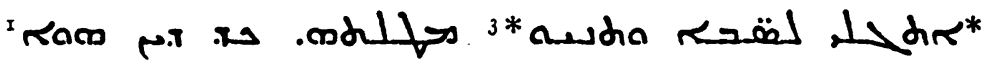

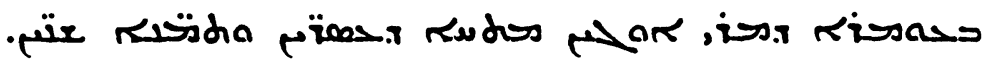

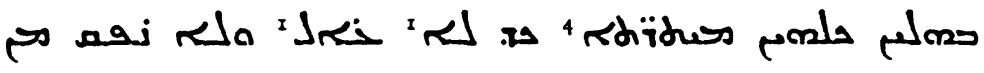

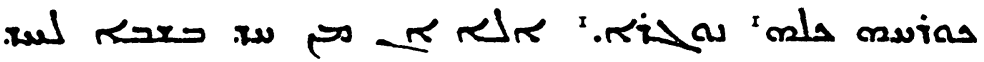

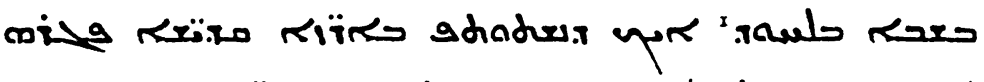

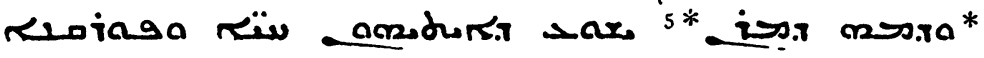

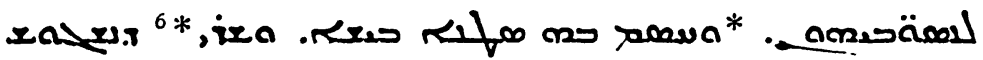

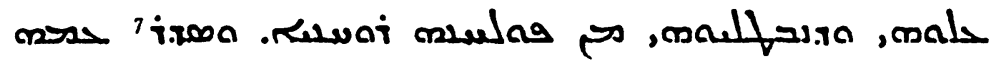

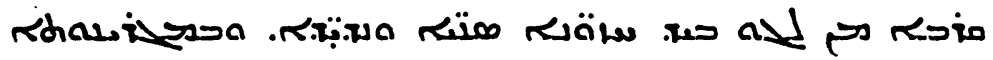

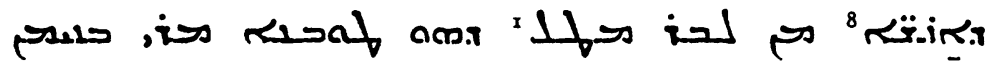

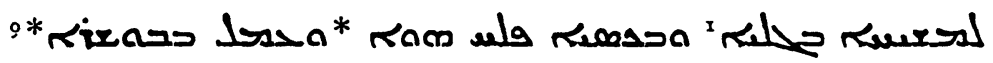

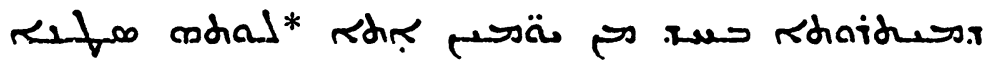

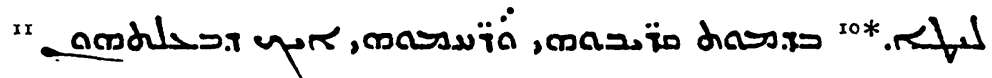
"s

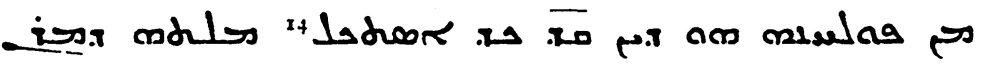

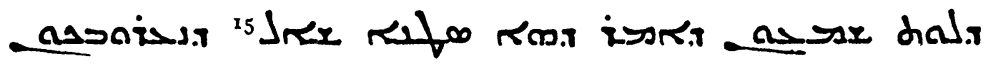

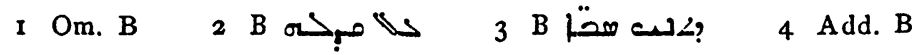

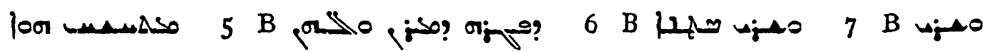
هـr

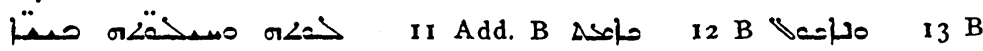

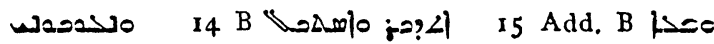




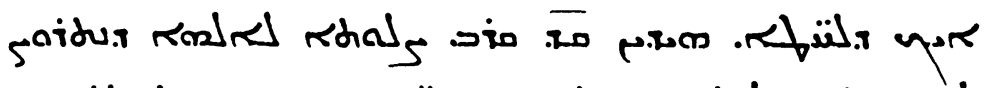

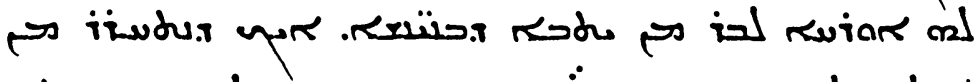

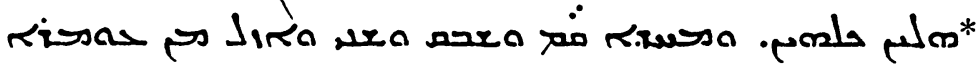

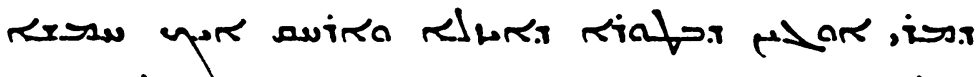

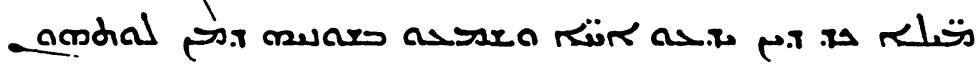

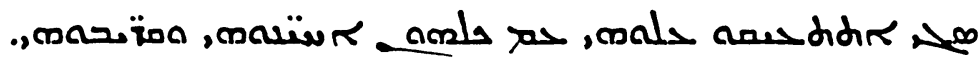

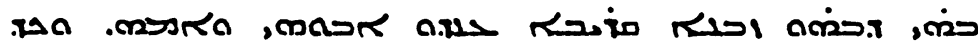

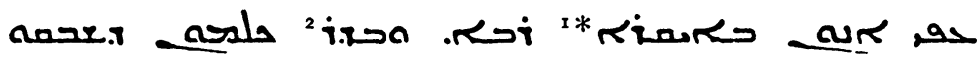

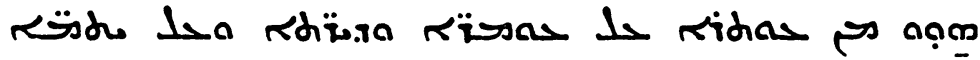

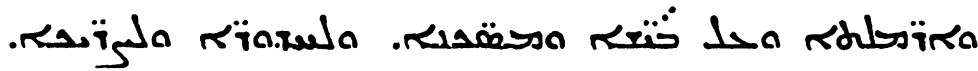

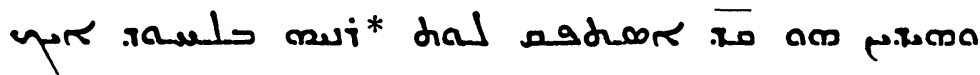

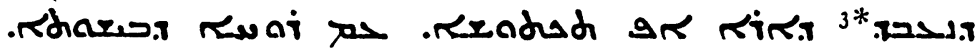

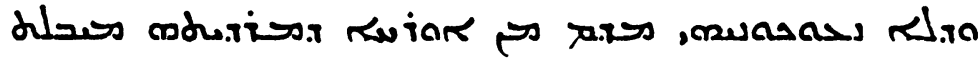

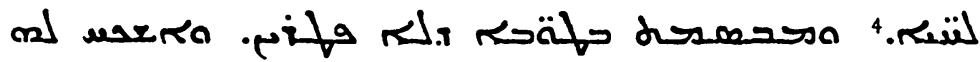

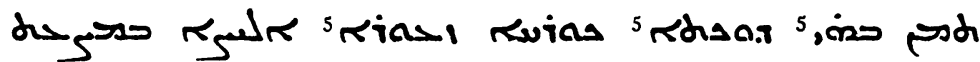

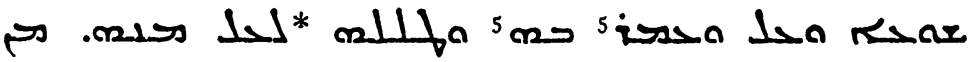

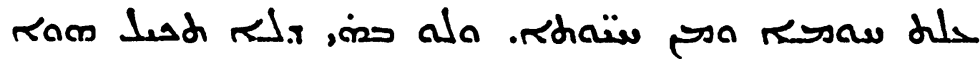
حل sis

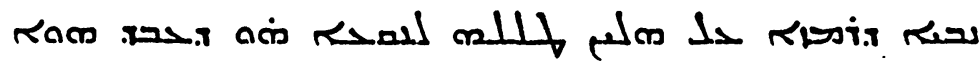

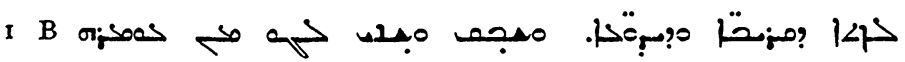

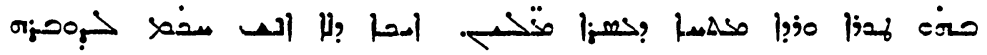

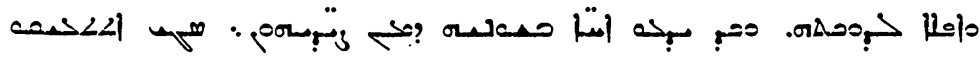

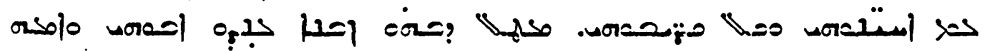

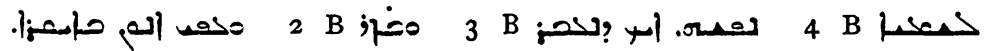
5 Om. B 


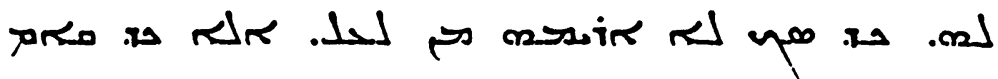

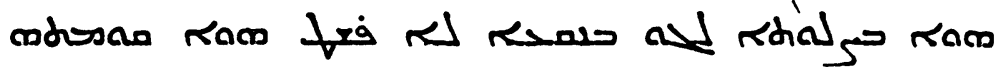
ram

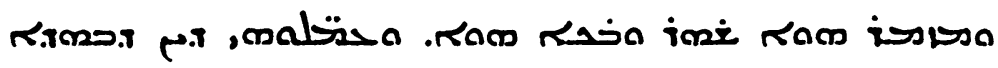
"*.

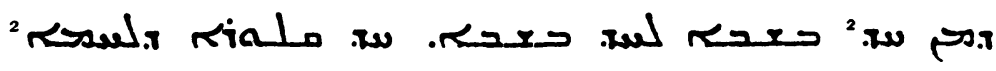

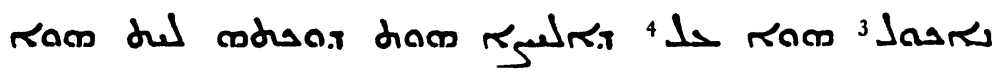

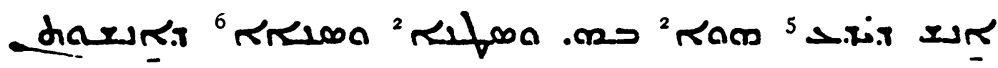

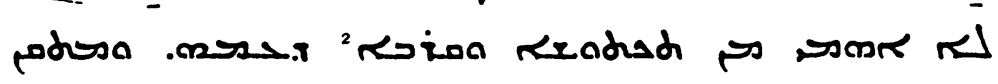
Ram

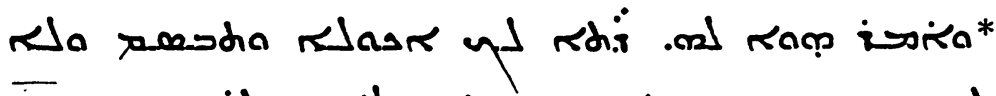

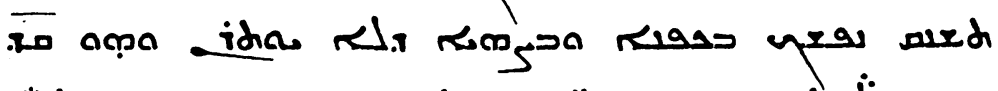

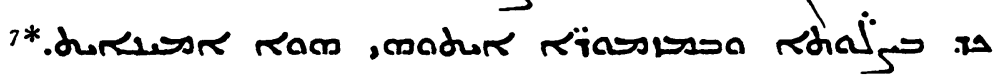

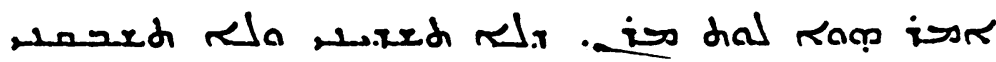

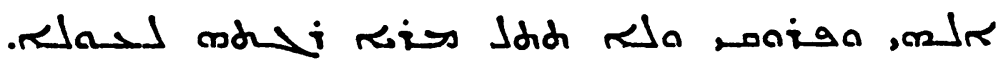

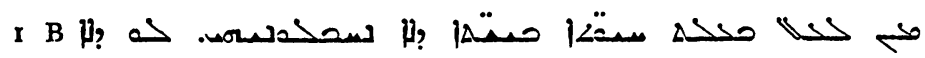

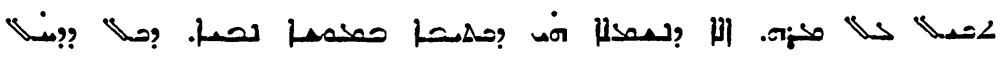

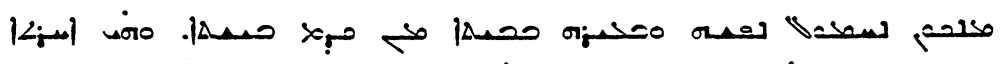

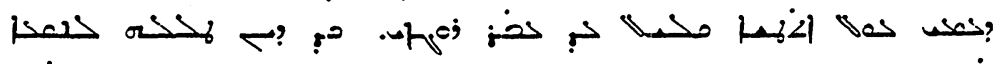
舟 lor

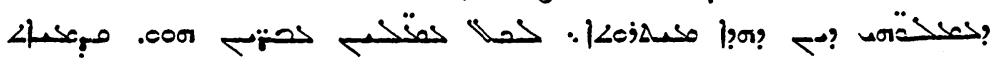

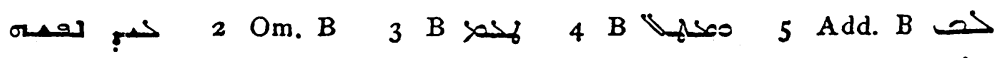

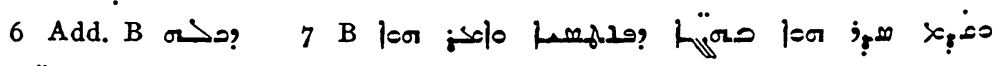
| 


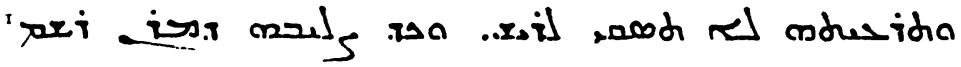

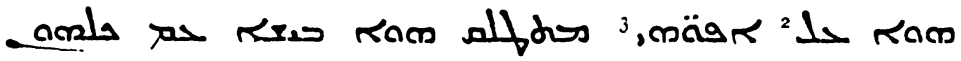
a

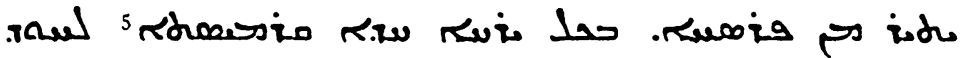

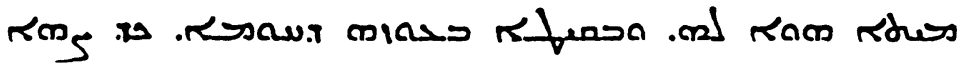

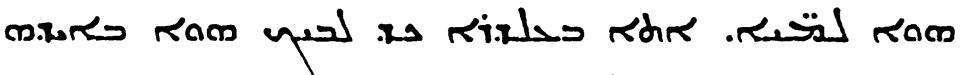

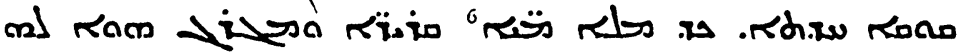

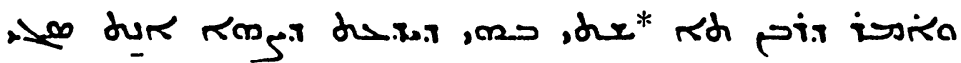

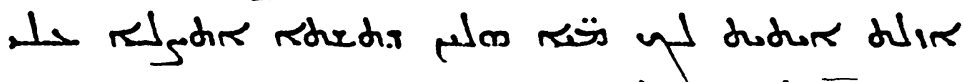

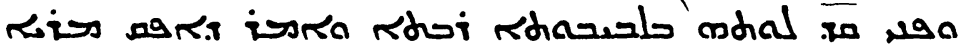

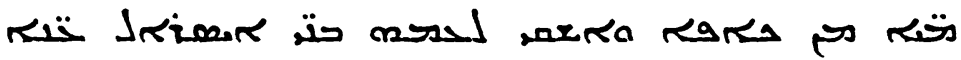
זs

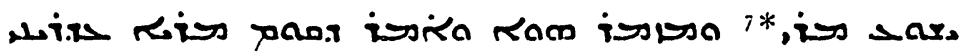

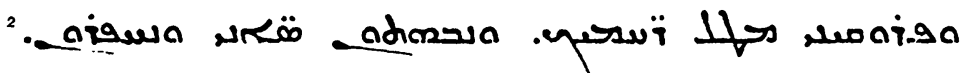

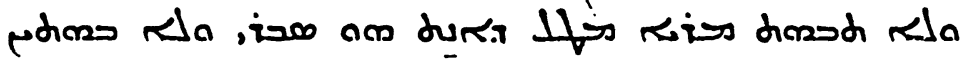

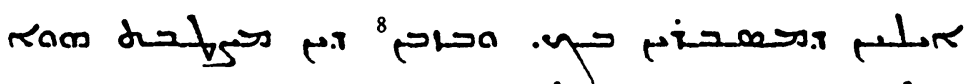

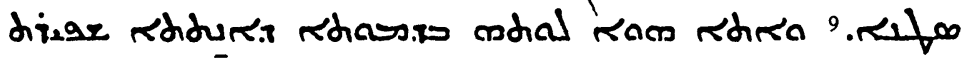

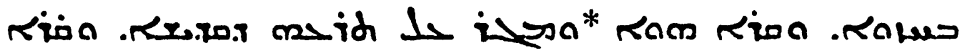

I B $i_{j} 2$ Om. B 3 B مكتبر 4 B

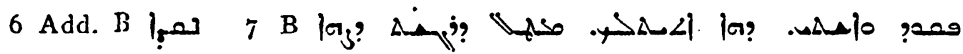
إد. lea

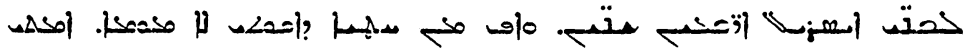

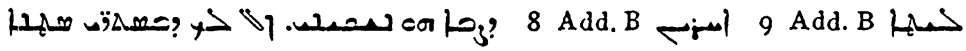




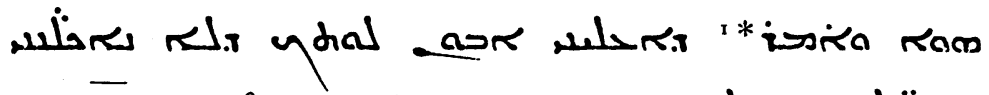

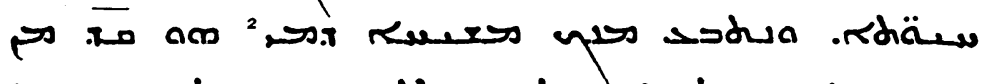

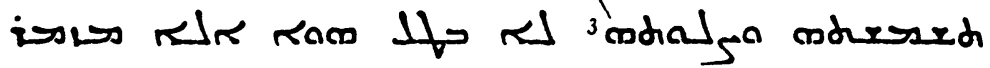

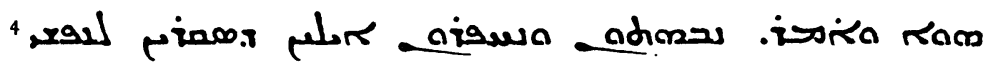

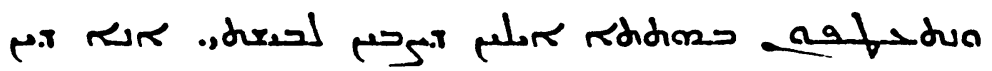

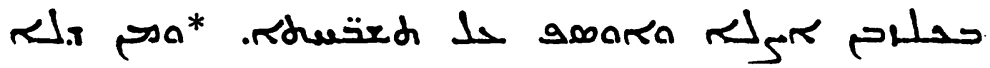

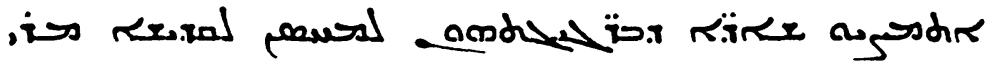

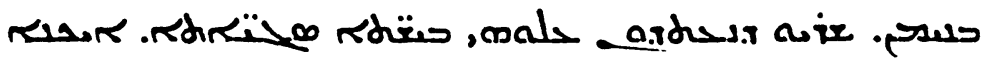

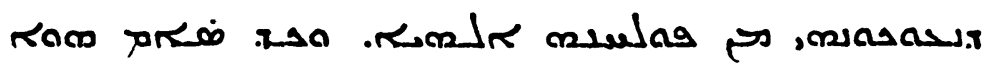

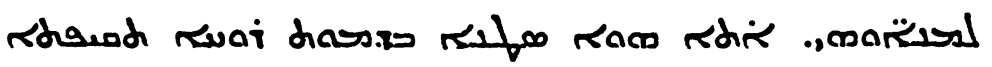

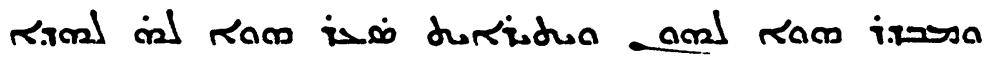

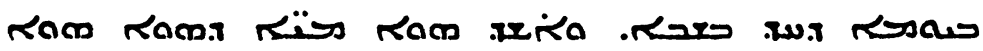
ram

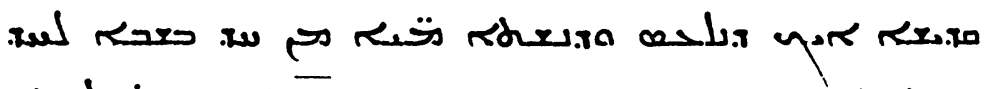

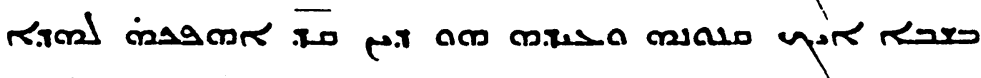

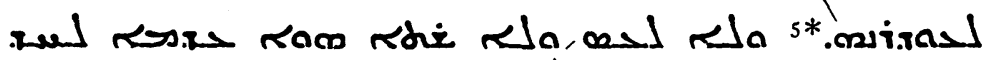

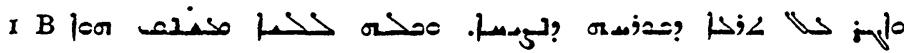

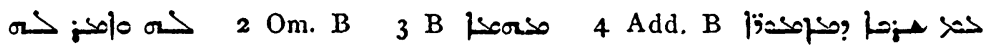

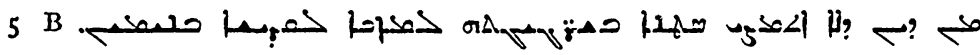

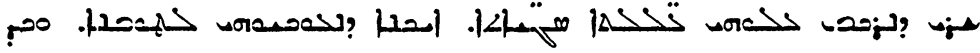

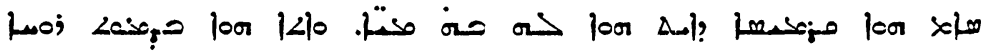

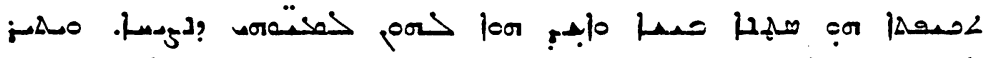
هذ: lear ?

? 
dacs

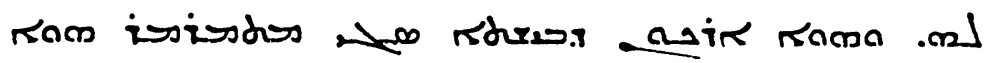

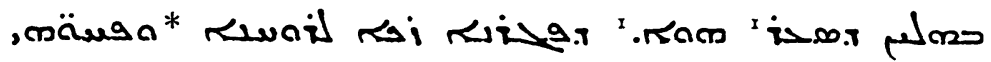

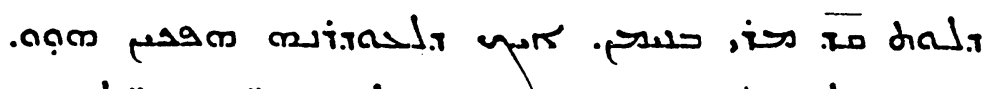
هח, ז.

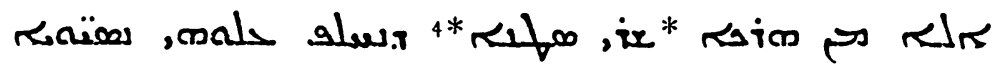
אתטils

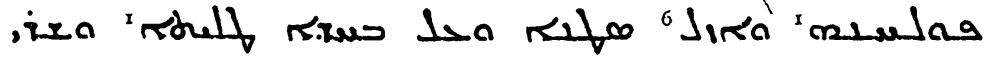

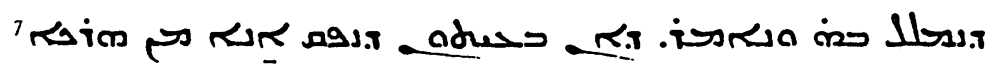

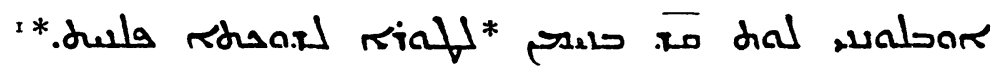

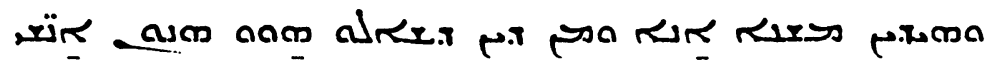

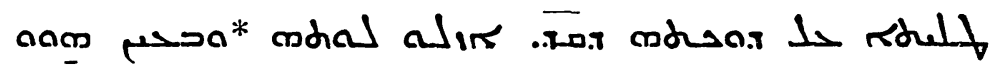

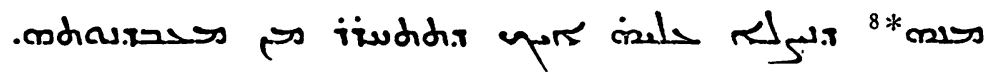

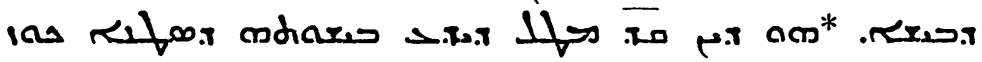
תल rom

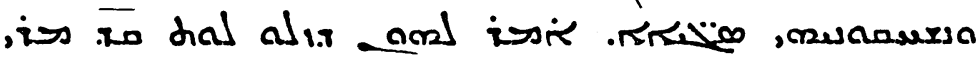

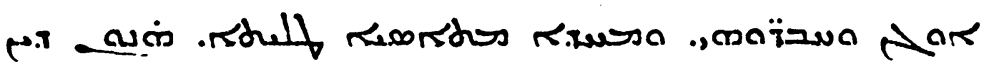

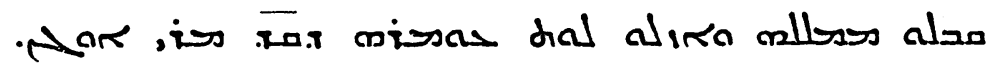

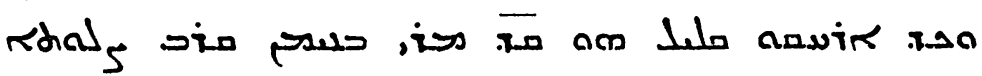

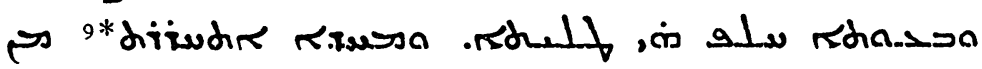

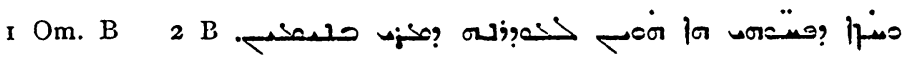

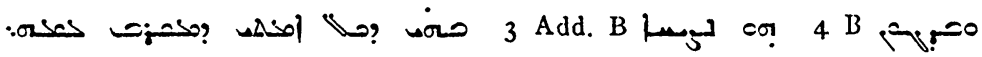
من 5 B 6 B

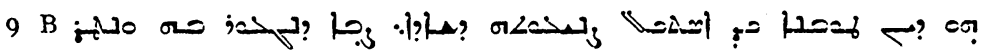




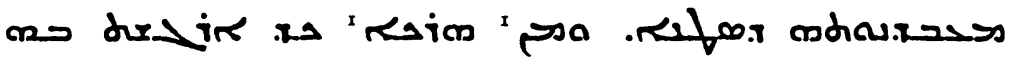

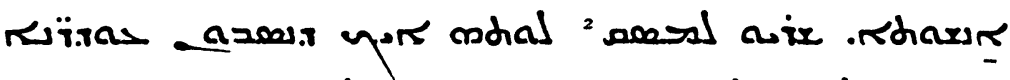

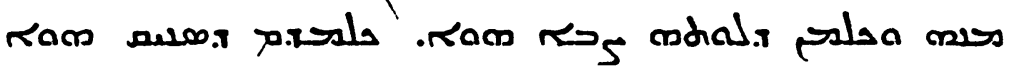

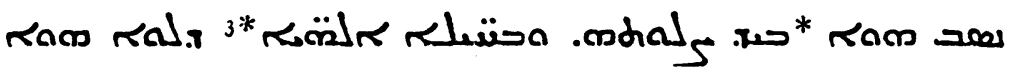

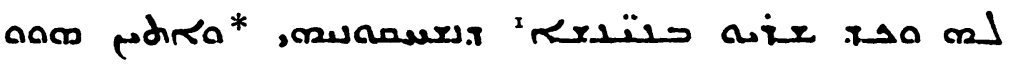

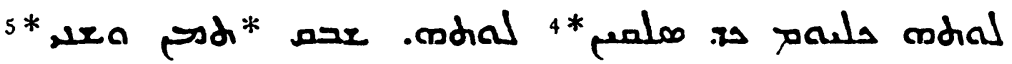
s.

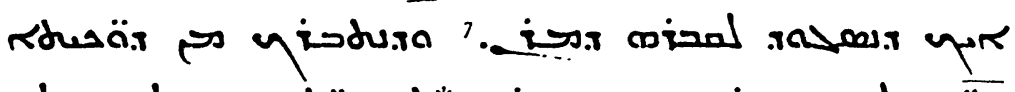

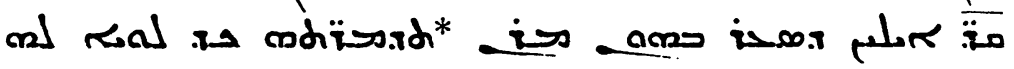

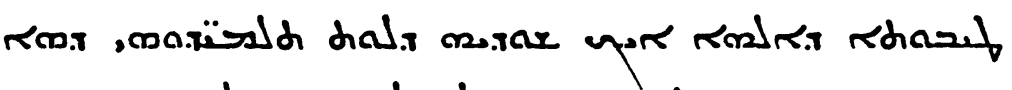

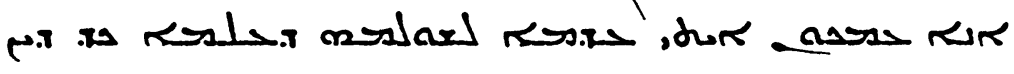

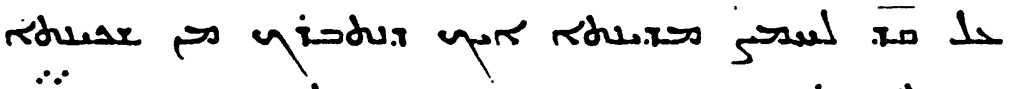

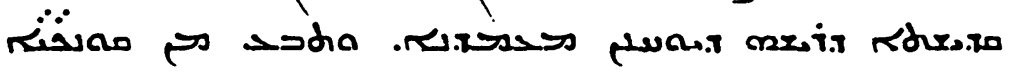
yisdux.

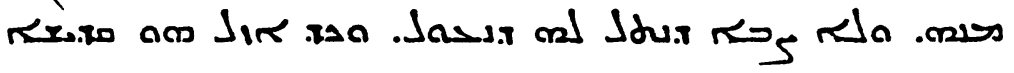

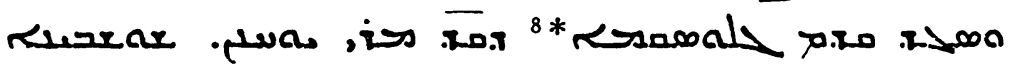

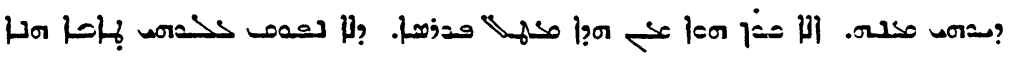

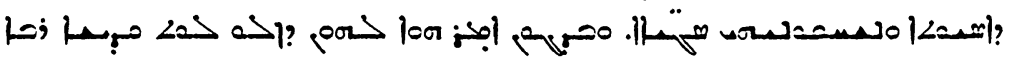

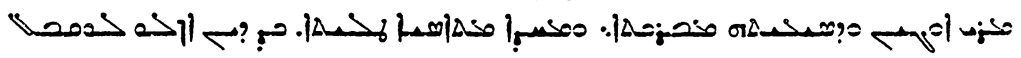

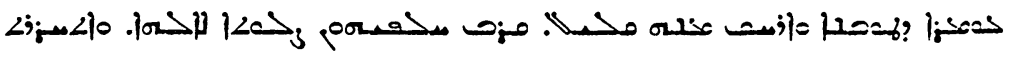
I Om. B 2 B 3 B lad,

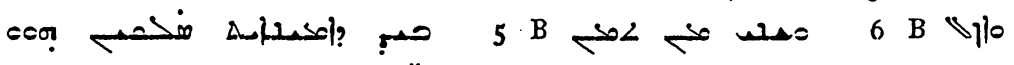
7 Add. B 2 B 8 B

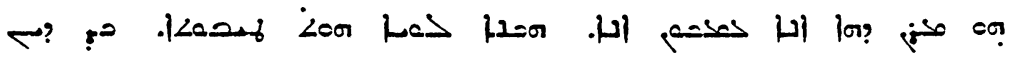

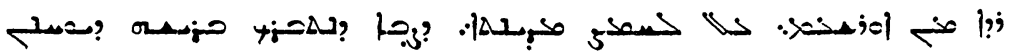




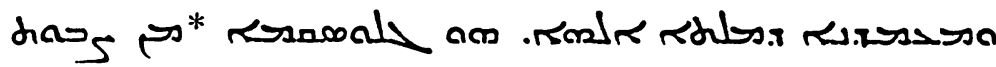

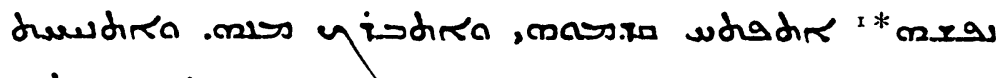
נara

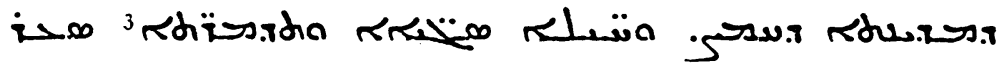

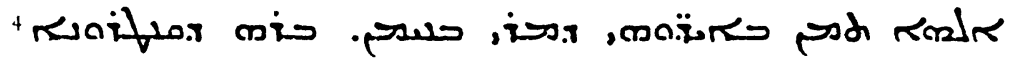

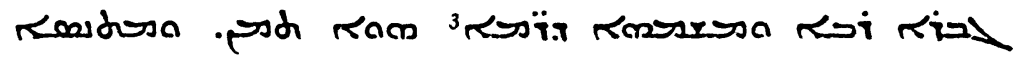

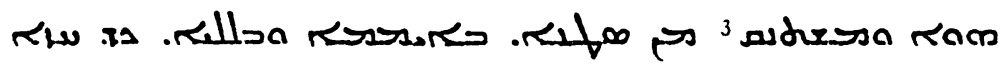

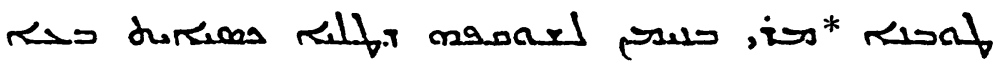

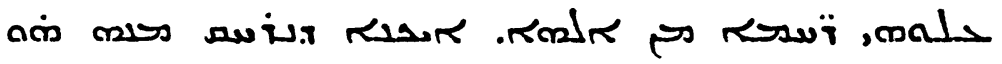

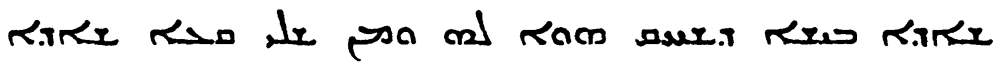

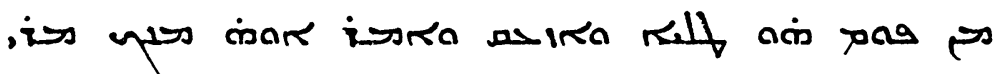
sust

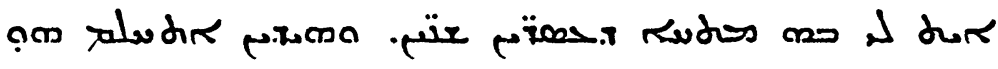

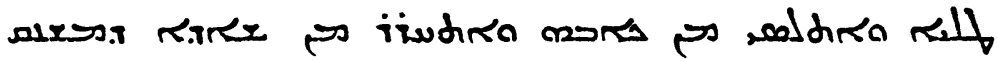

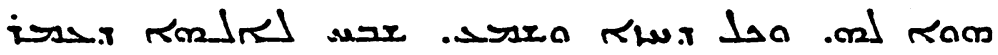

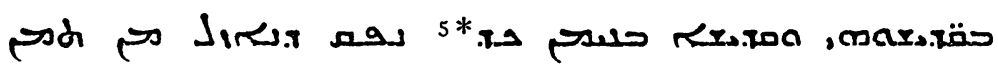

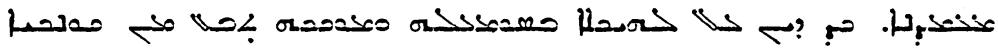

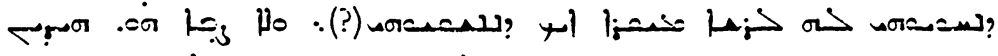
का का

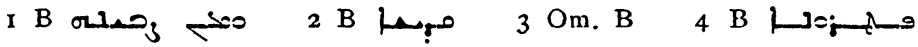

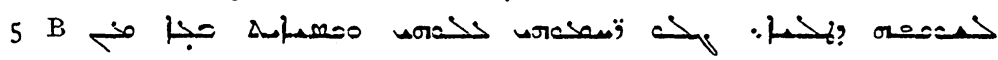

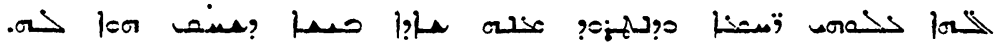

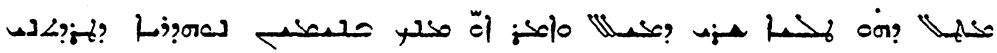

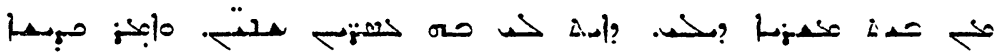

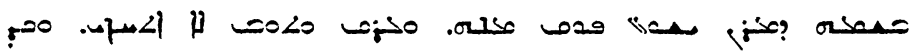




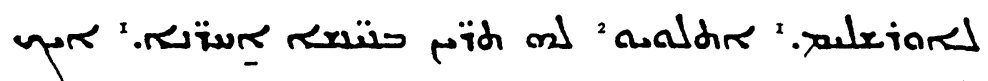

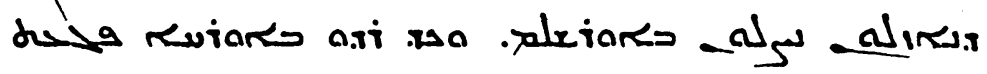

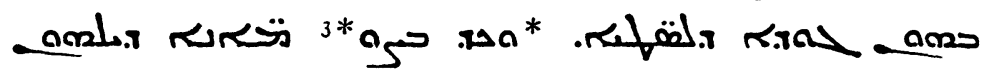

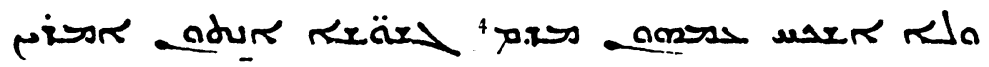

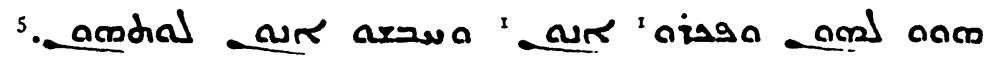

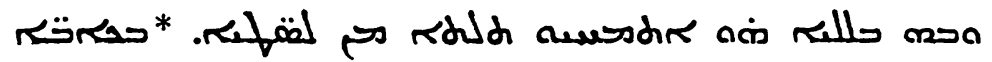

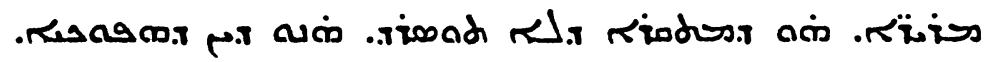

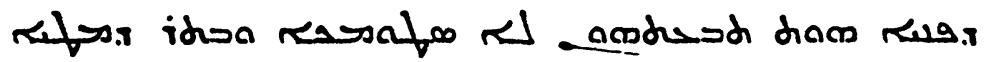

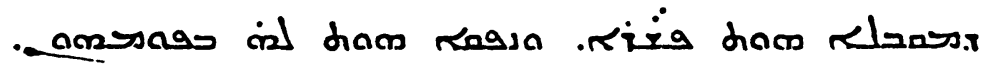
ara دuلs נark

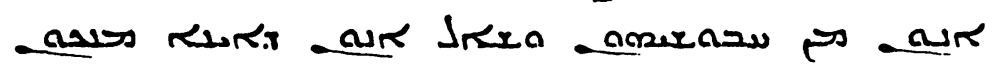

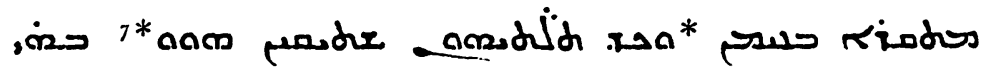

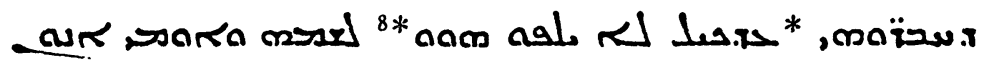

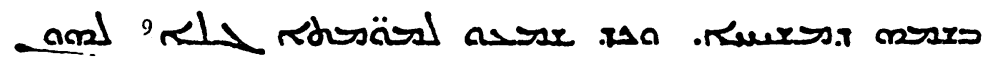
1)

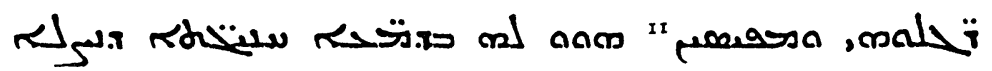

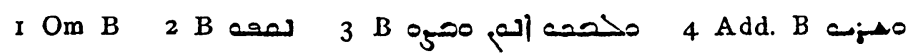
on

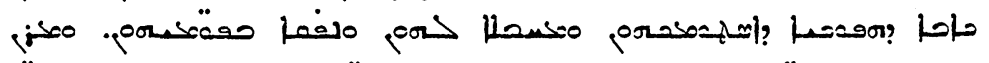

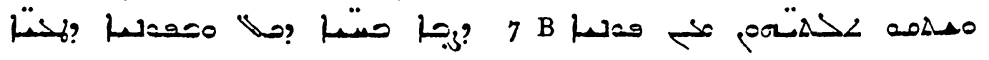

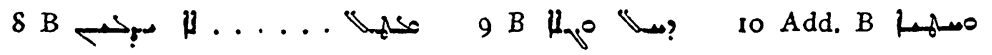
II $B$ مهن 


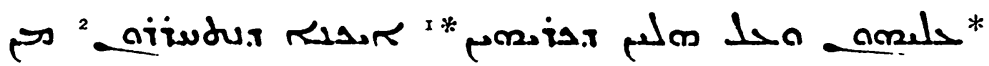

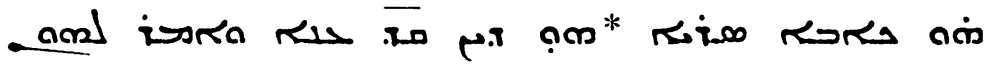

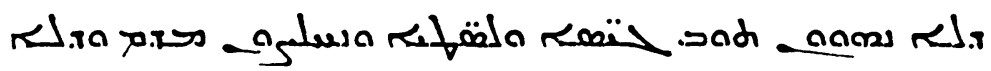

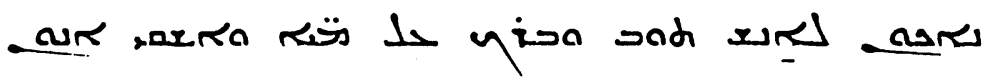

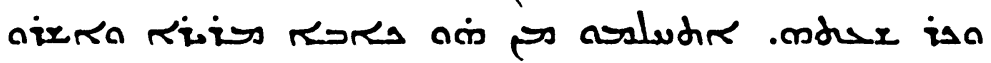

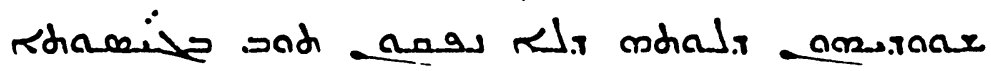

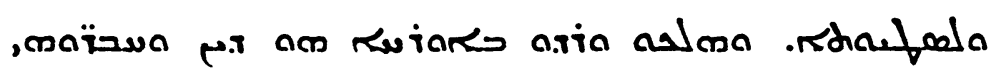

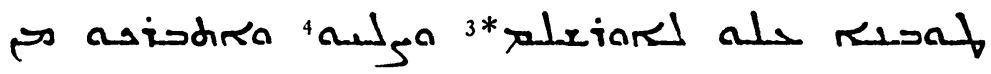

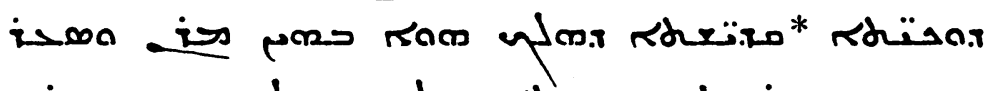

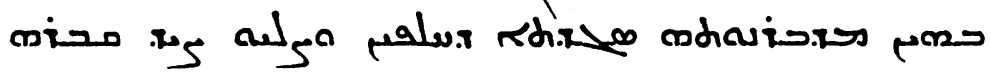

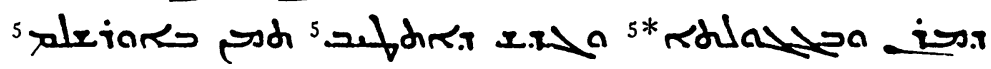
"

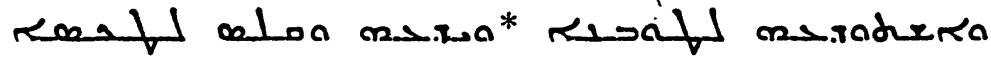

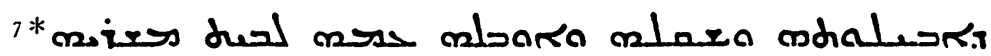

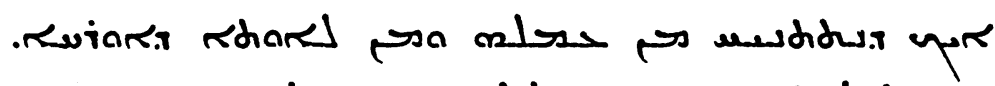
rhasars and adra* lelo rdosä mdial idan

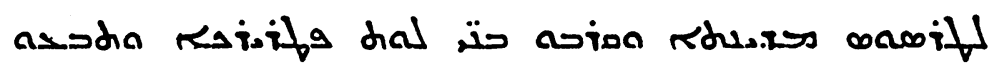
, aud pour

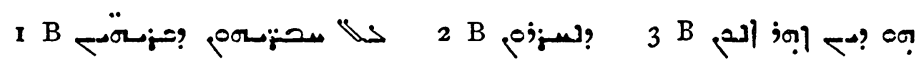

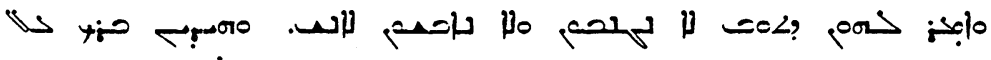

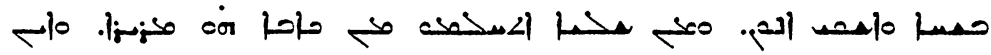

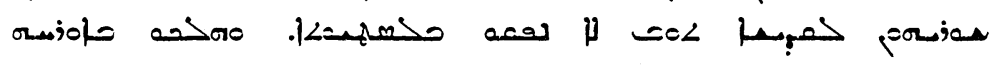
معصil

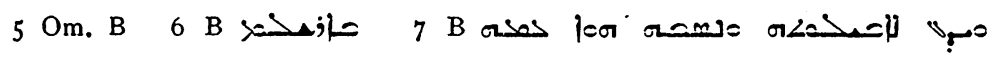
antal or alo 8 B lẹr too 


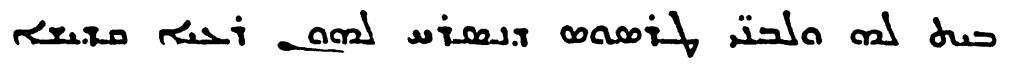

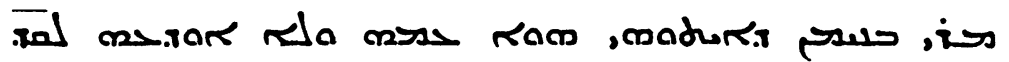

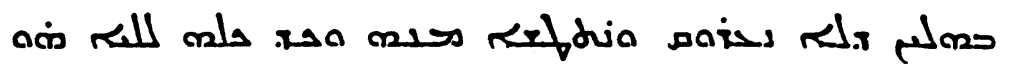

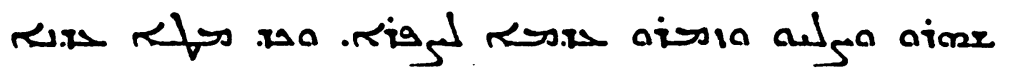
תمוֹ خ

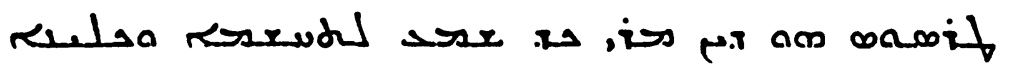
ת.

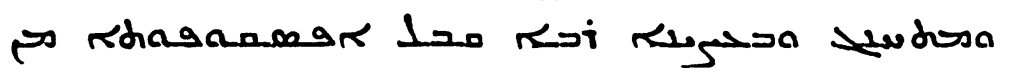

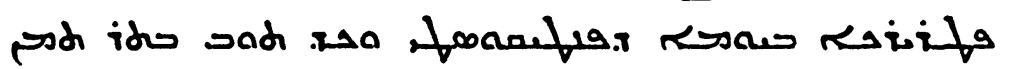

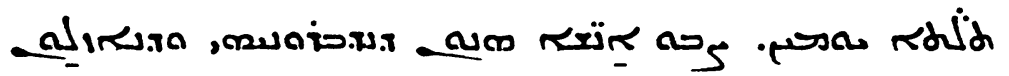

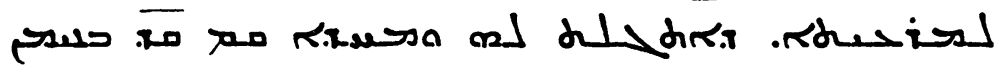

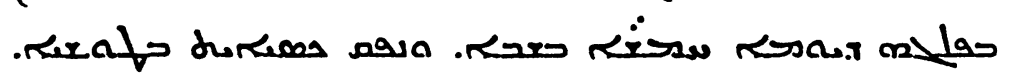

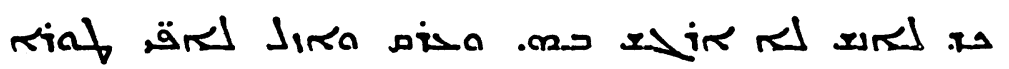

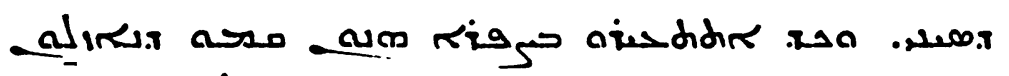

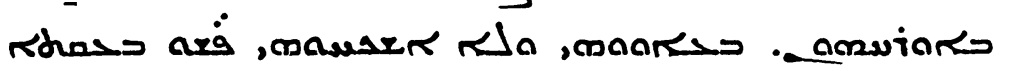
T.

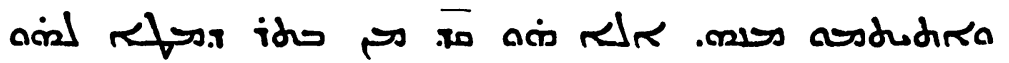

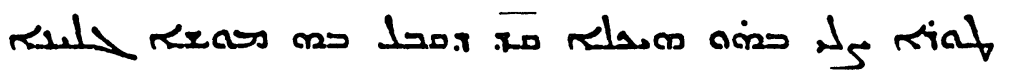
אר

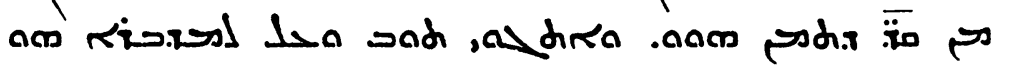

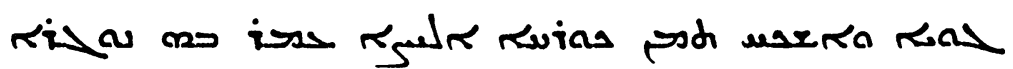

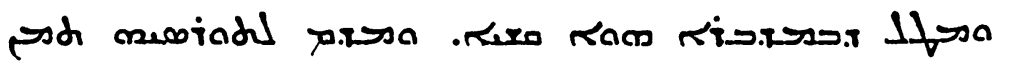

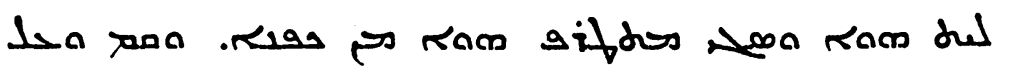




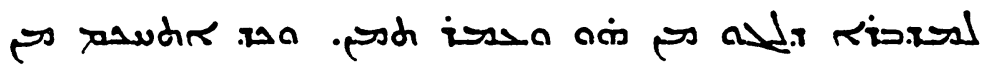

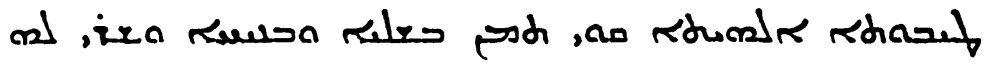
rsaga rimx.

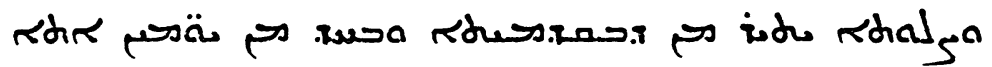
תلs alas als, masasa

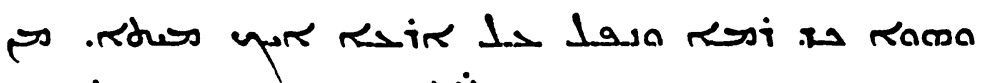

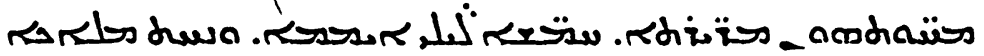

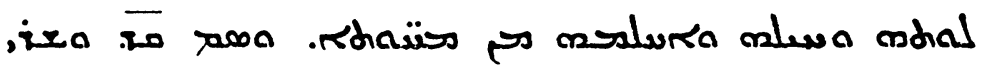

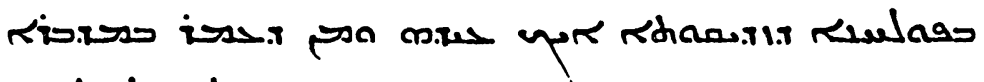

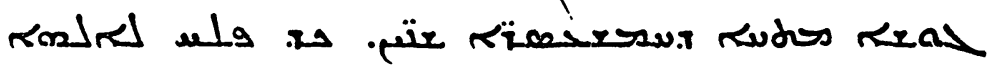

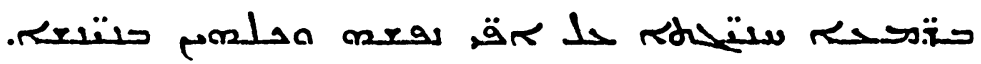

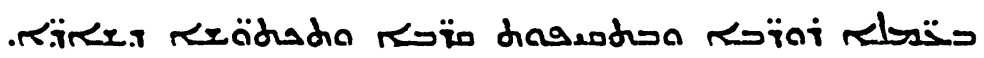

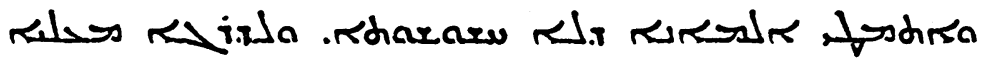
Th

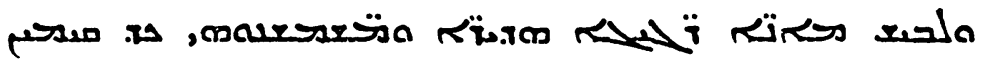

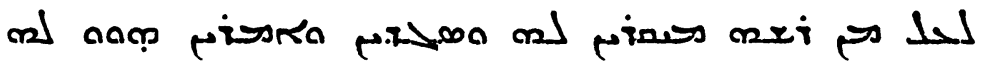
لمتx. ridus

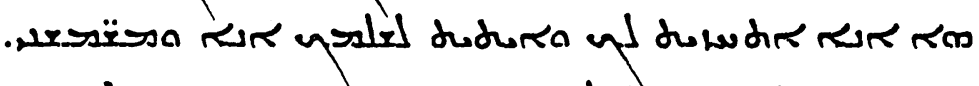

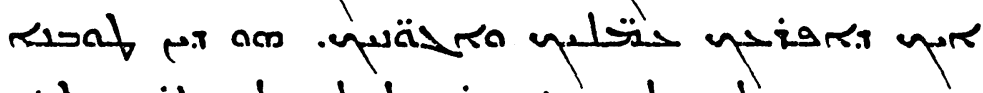

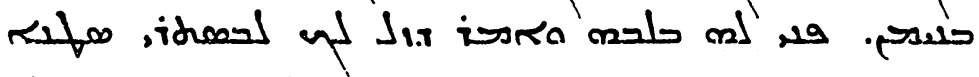

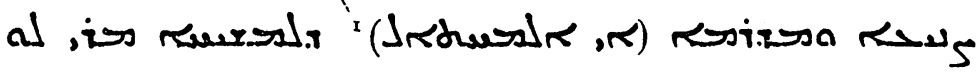

I Glose arabe.

7.eitschr. f. Assyriologie, XII. 
دلده x.רdr

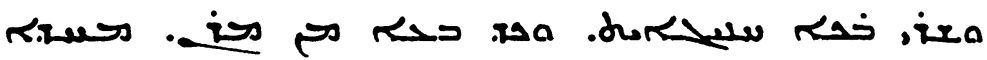

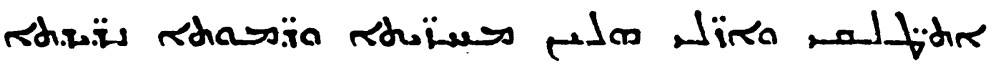

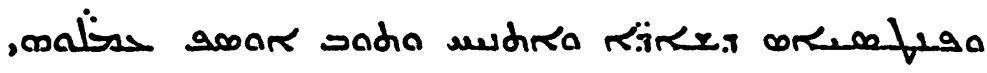

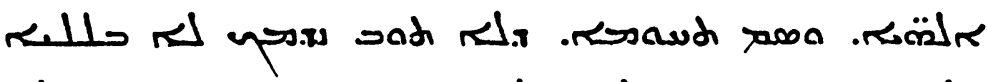

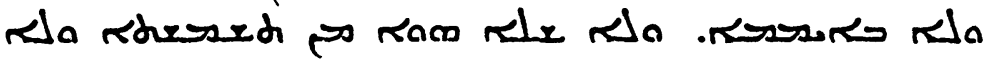
תק s six

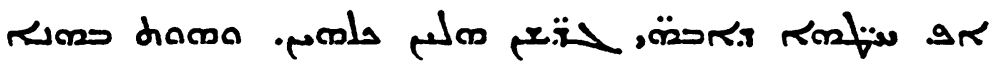

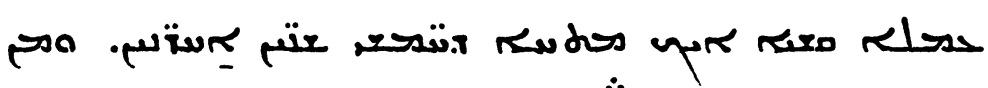

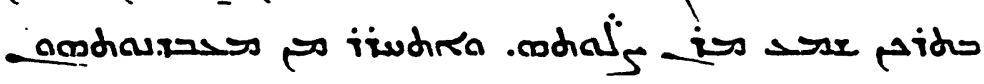

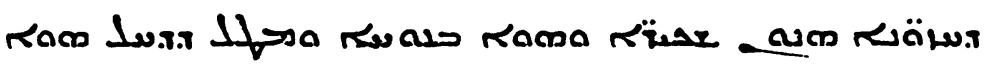

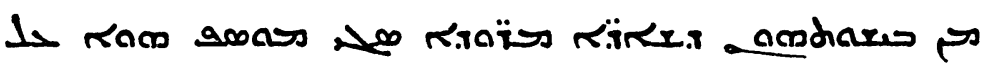

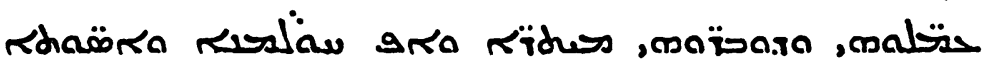

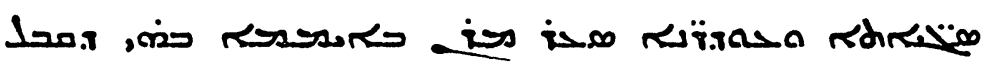

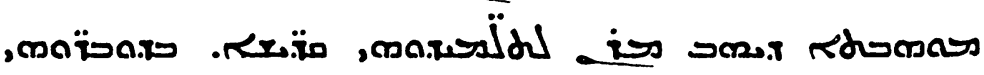

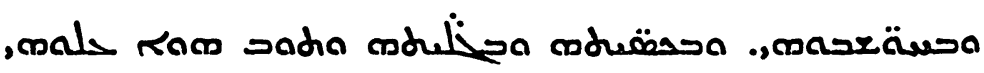
עall

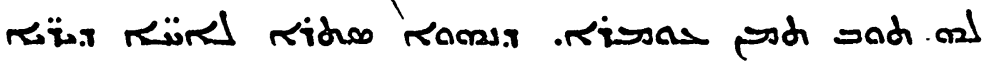

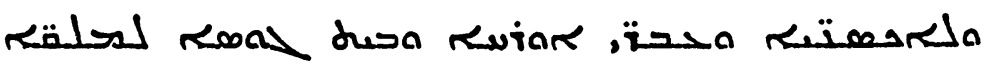

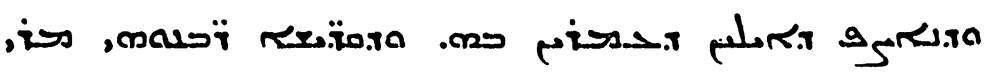

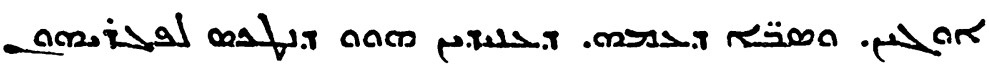
yisdus 
s , غ.

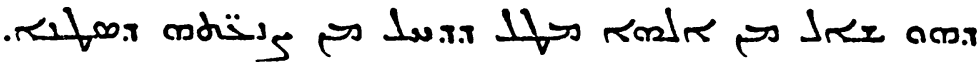

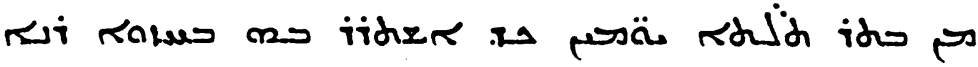

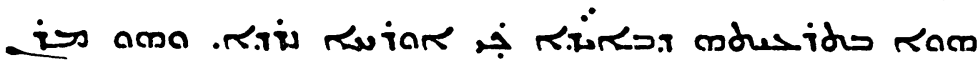

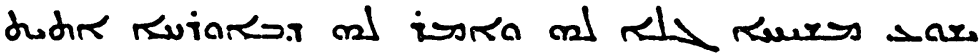

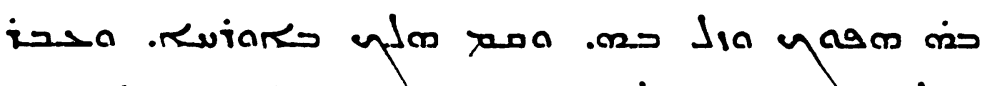
مam כח.

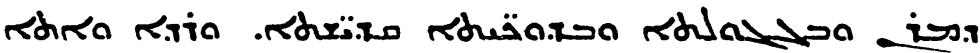

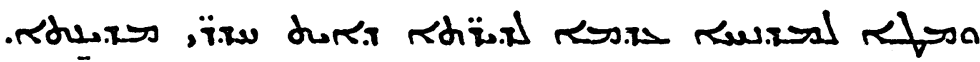
ast

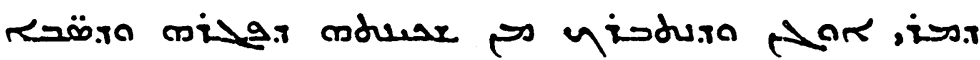

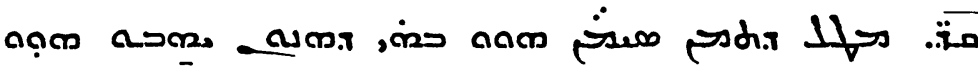
s

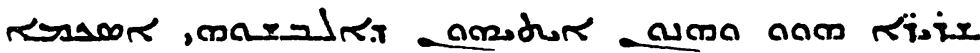

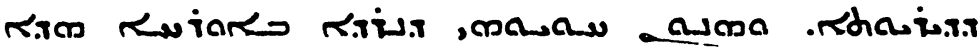

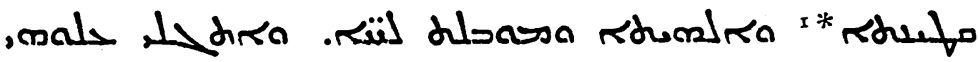

I B

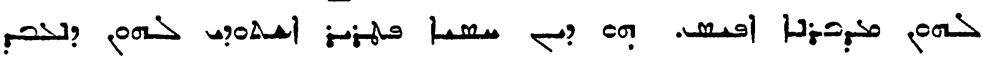

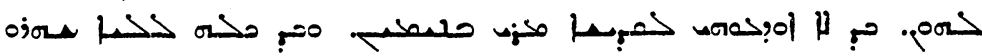

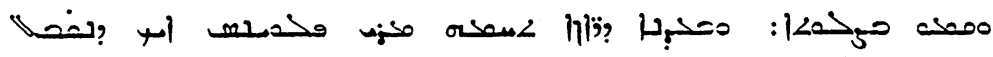

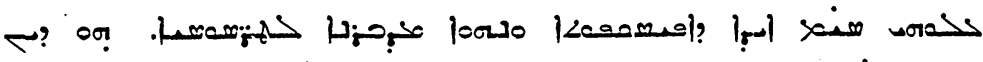

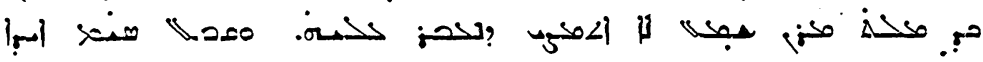




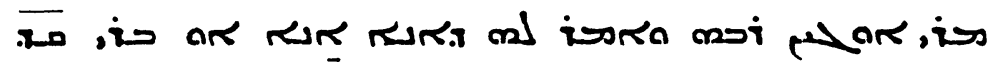

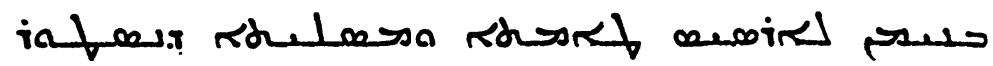

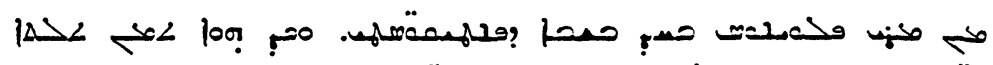

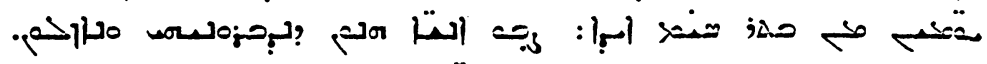
onc

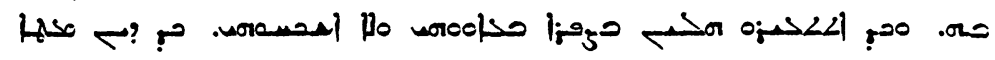

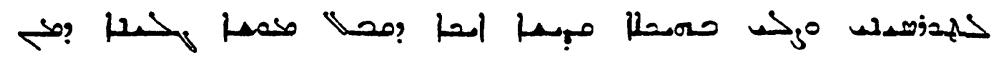

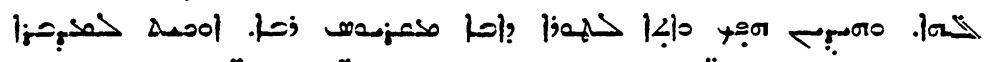

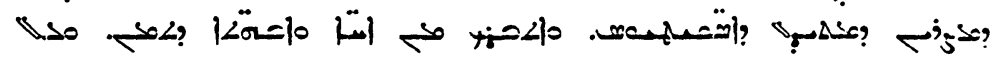

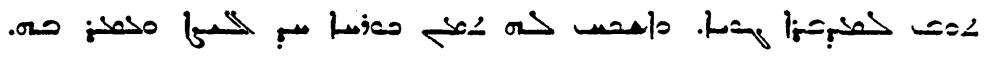

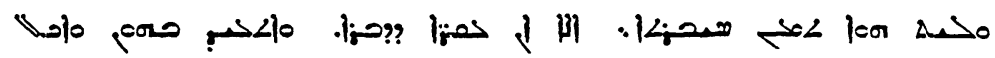

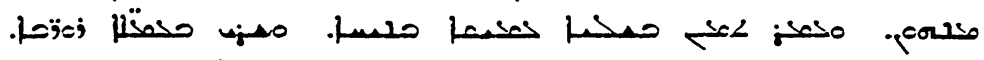
ror

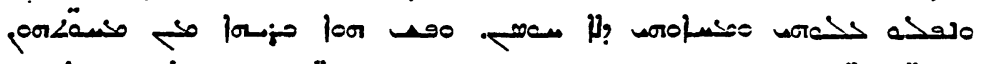

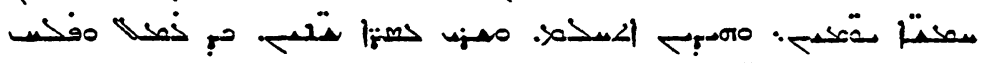

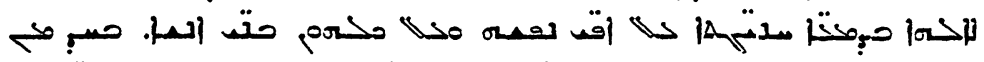

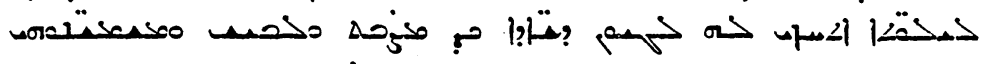

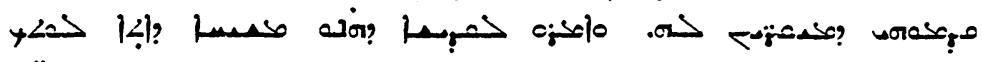

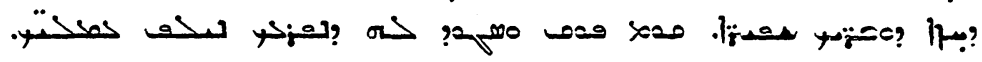
! ea

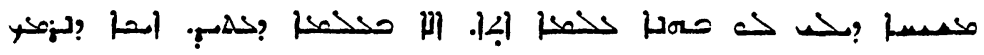

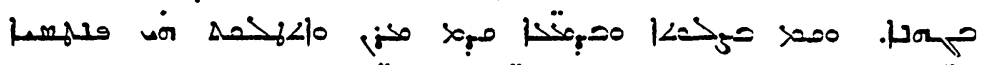

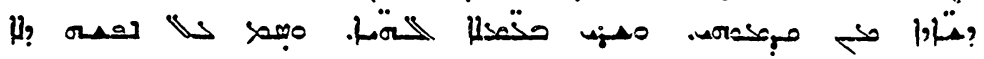

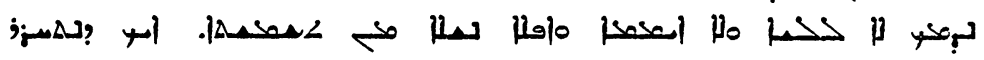

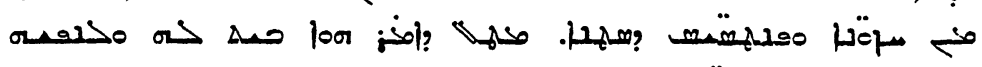

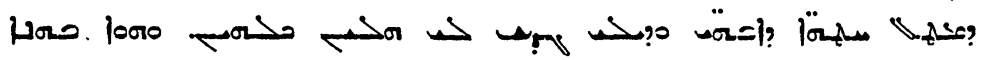

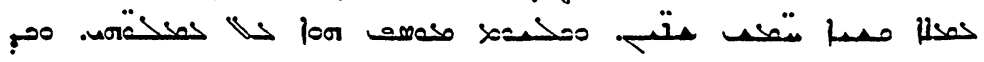

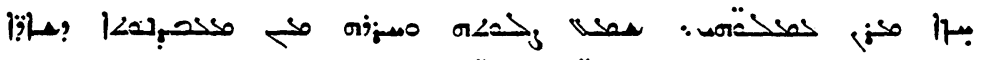
lere 


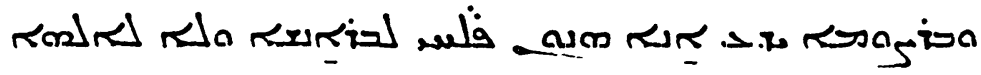

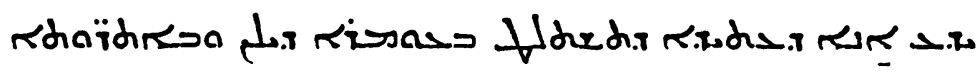
תדr.

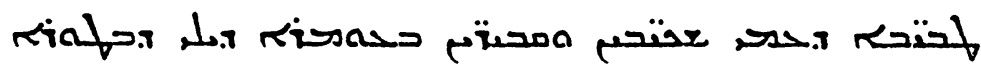

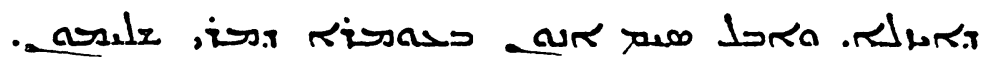

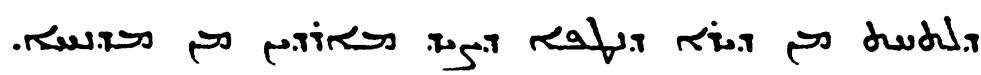

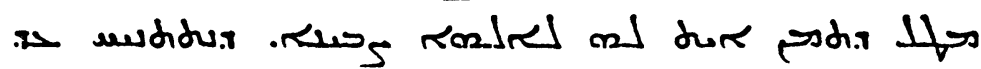

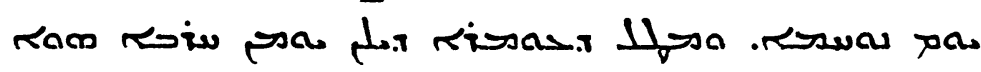

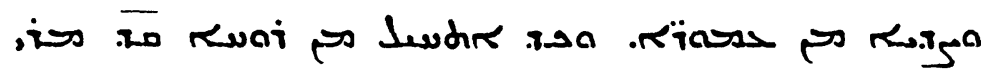
حسدק הiafl م. Tא.

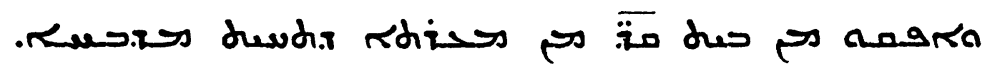

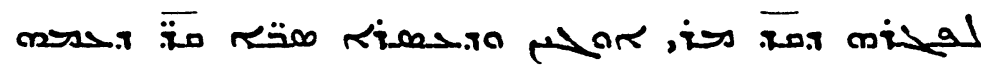

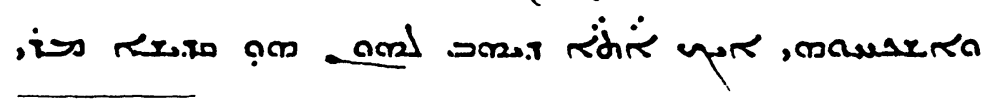

or

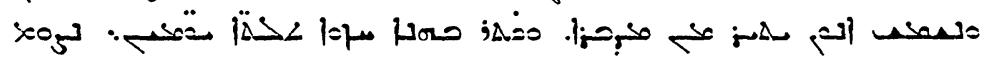
كما |然 صמل.

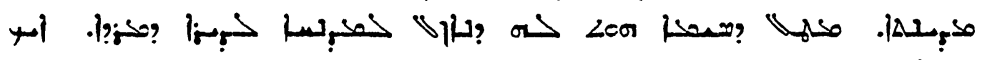
000 ه

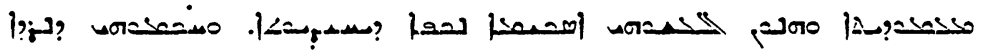

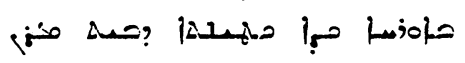




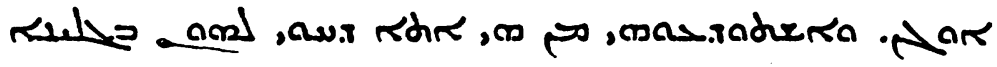

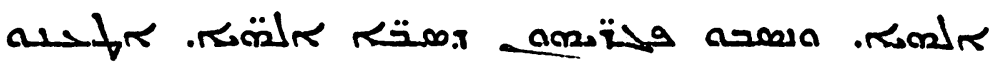
مas ratar

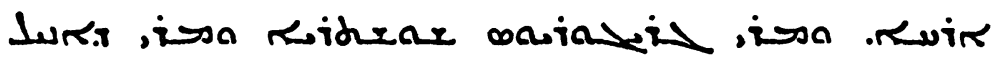

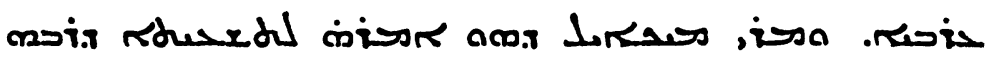

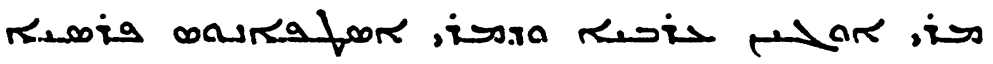

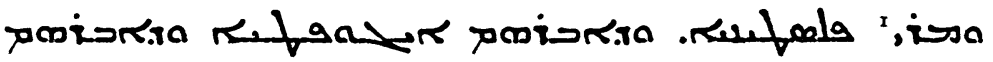

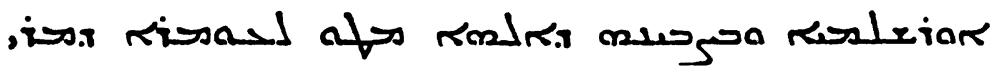

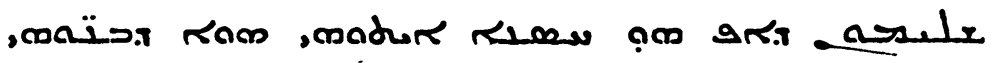

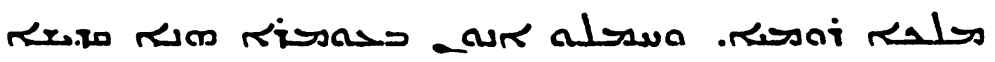

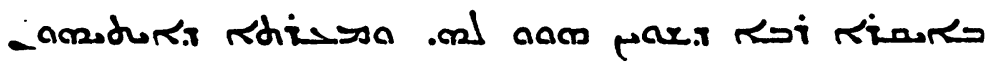

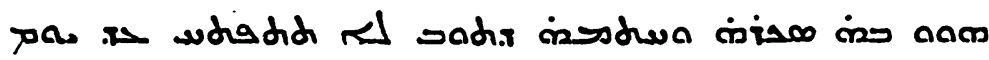

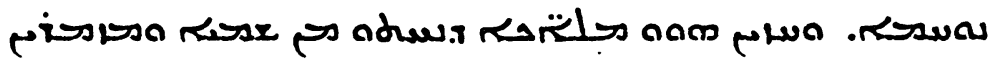

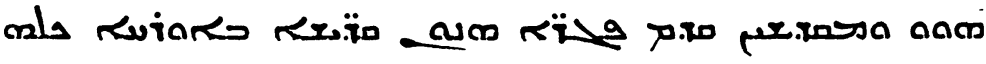

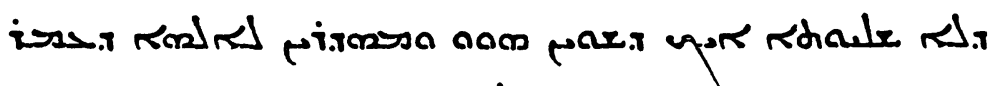
sمت.sara

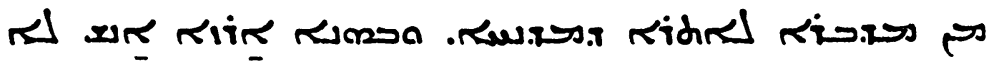
אוֹ

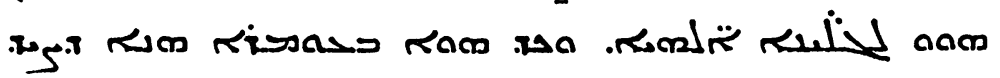

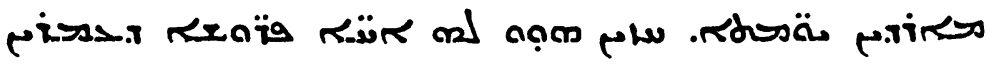
T. salan

I Manque un nom. 


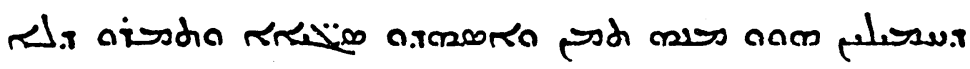

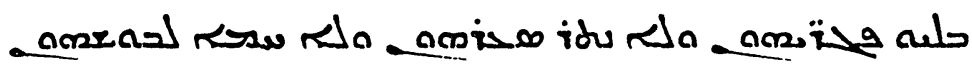

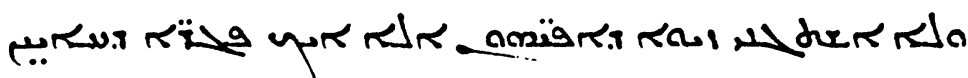

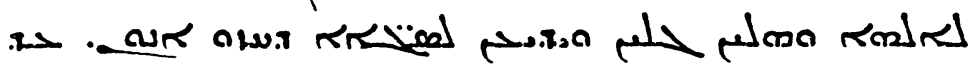
rosticastarla resad

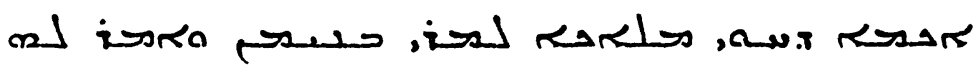
$\therefore$ הandials

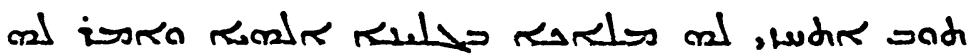

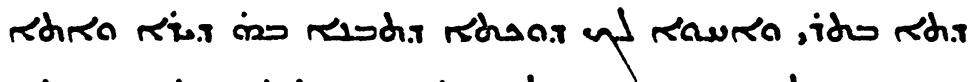

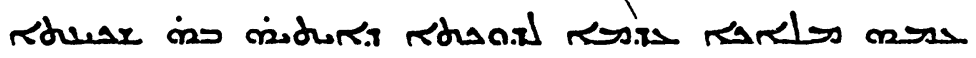

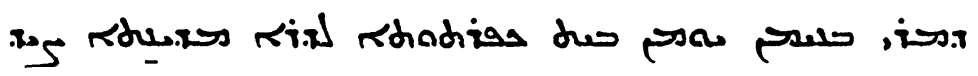

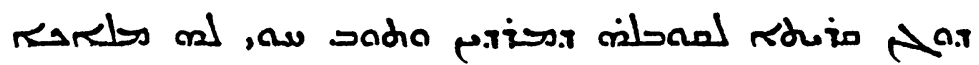

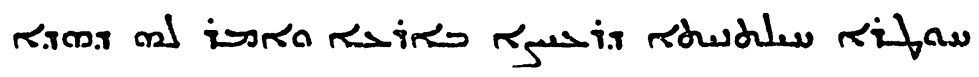
o

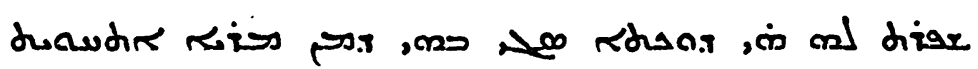

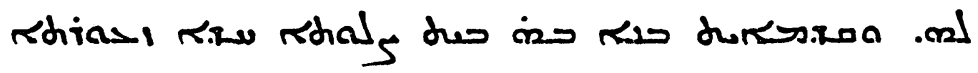

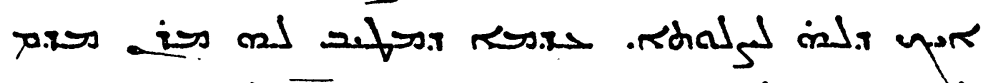

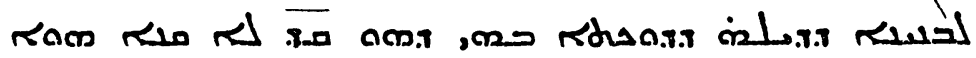

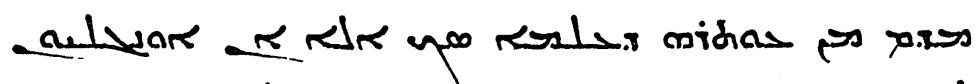
ת raul

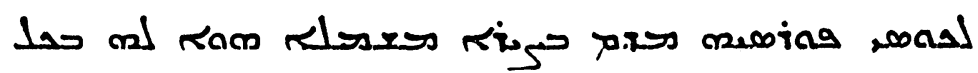

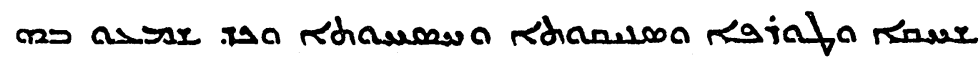

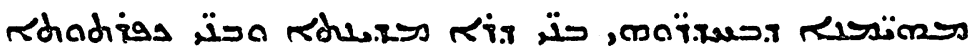

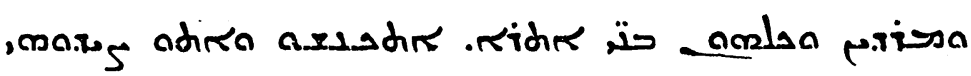




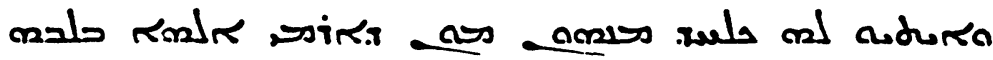

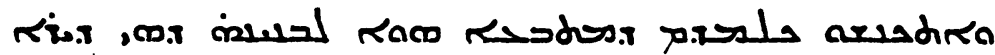

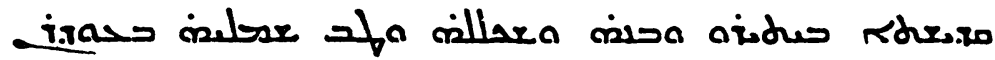

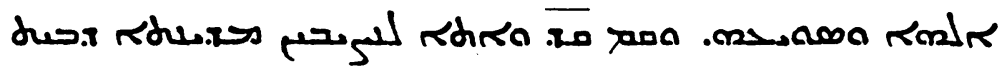

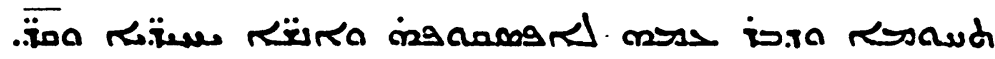

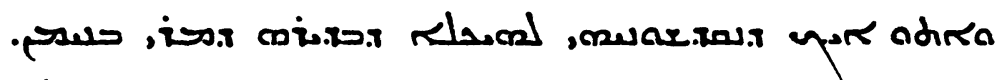
als مل

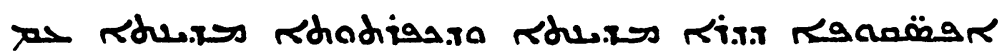

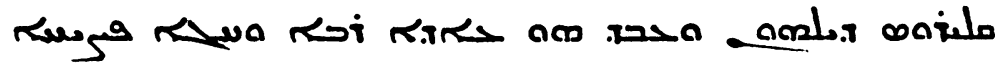

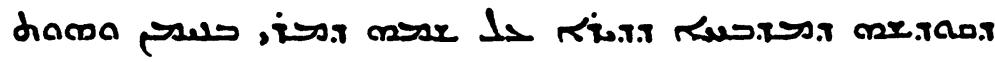

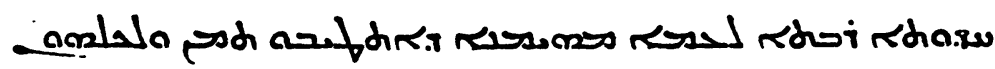

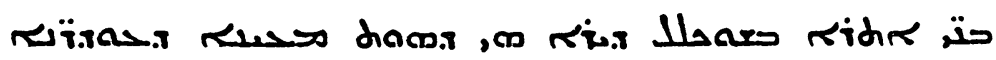

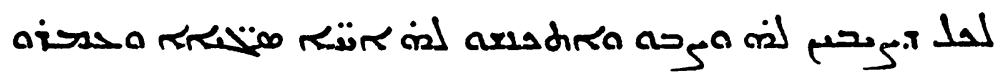
s'

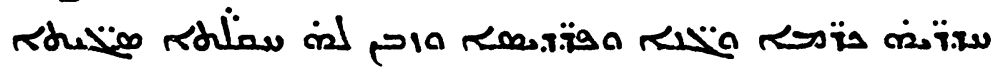

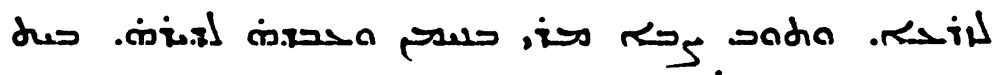

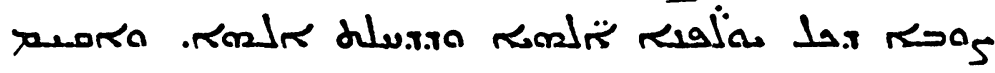

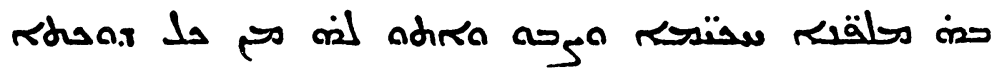

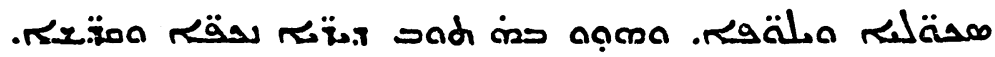

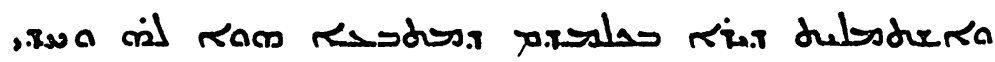

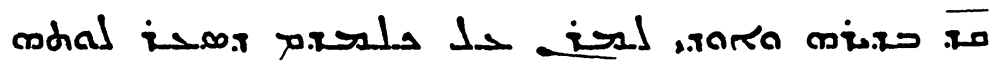

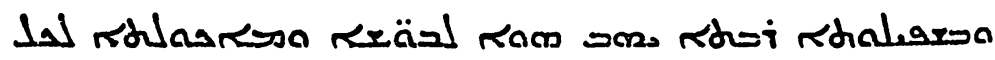
תק "s 


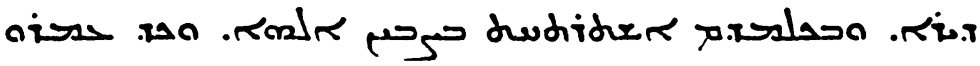

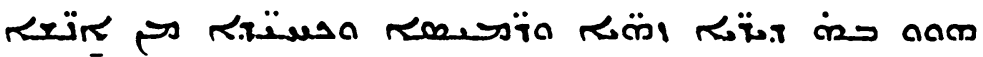

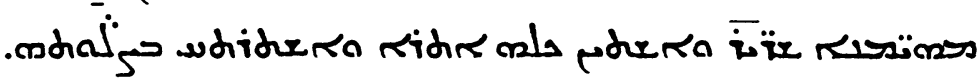

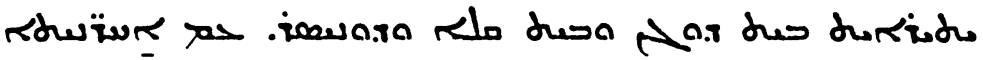

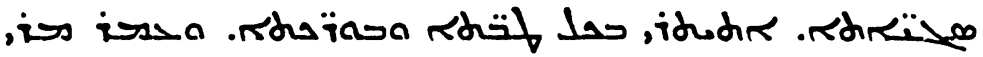

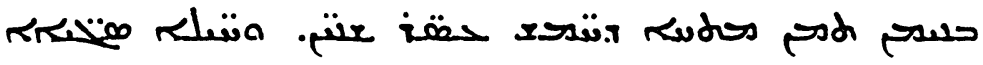
arom محبتمك ف هاخ مaلs תום

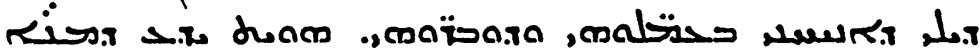

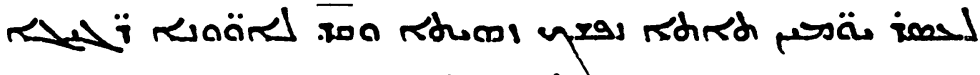

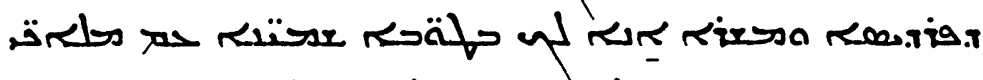

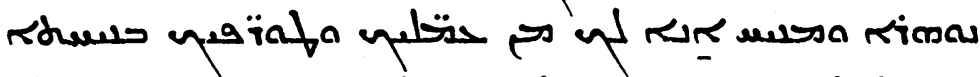
க, ז.لحلم.

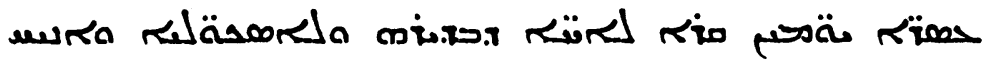
אתa תمكلي Rhachis

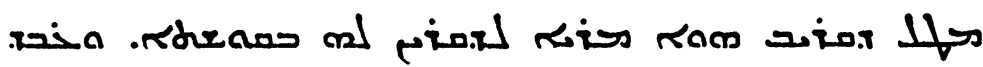

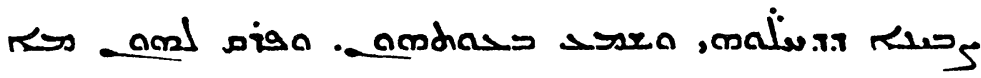

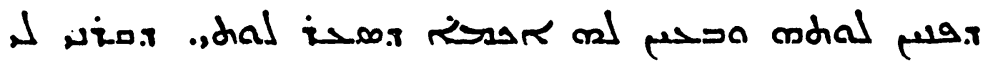

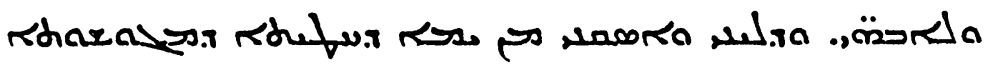




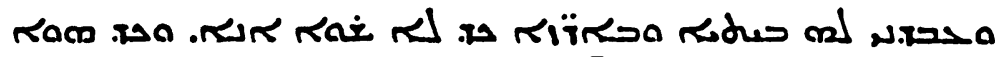

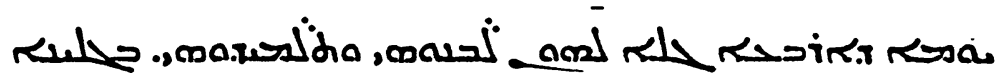

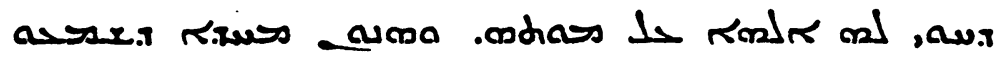

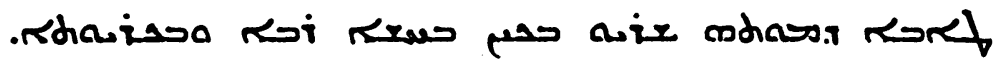

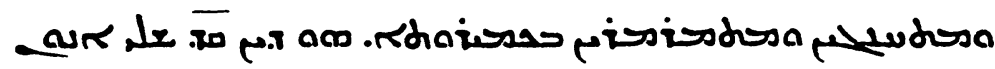

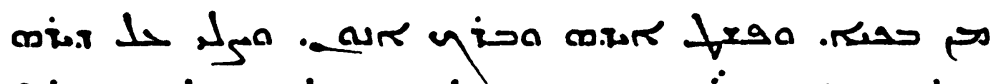
م ملs

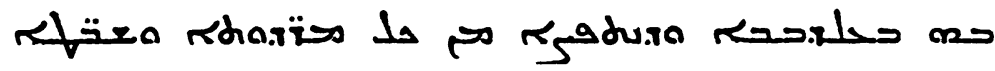

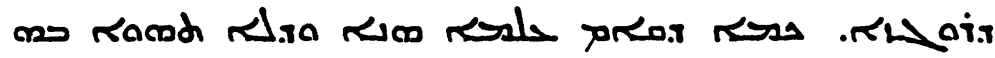

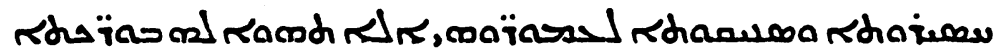
al محiٔ אل זs

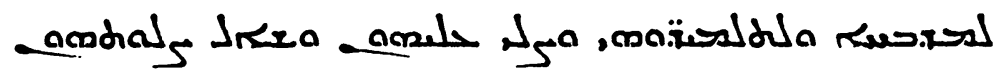
תrac ه ז

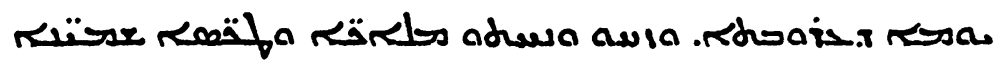

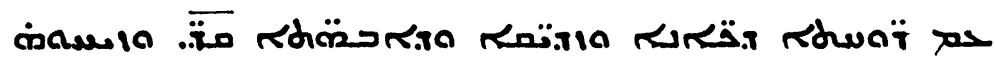

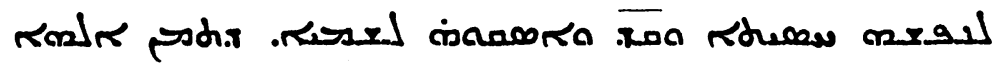
נaic

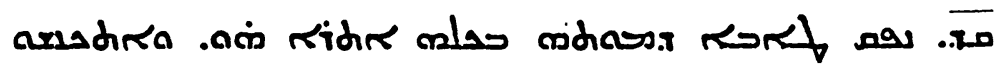

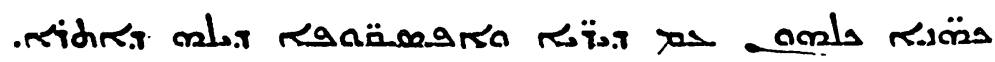

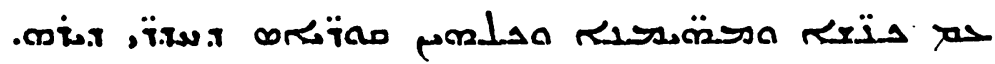




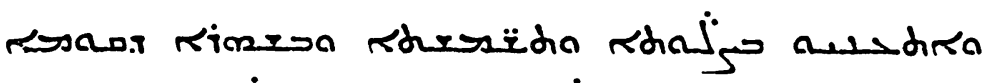

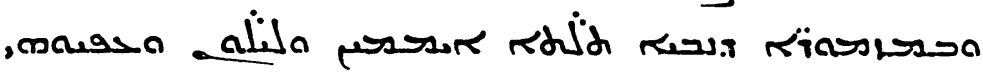
a asso

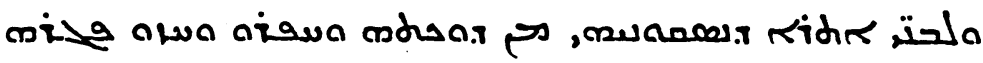

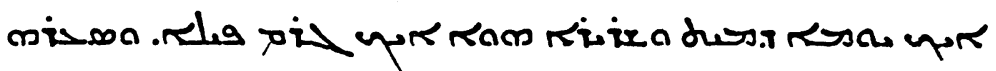

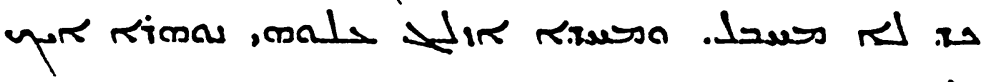
rh.w ruiat a ק,

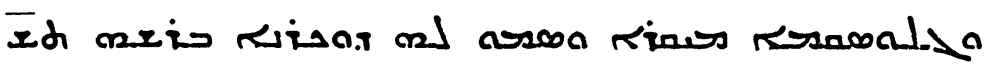

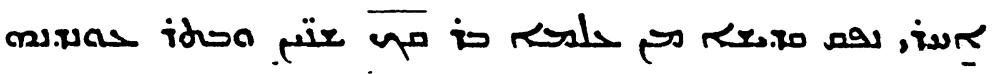

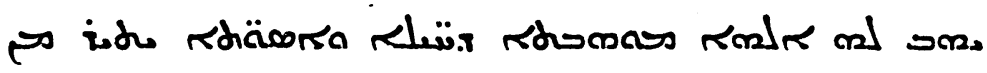

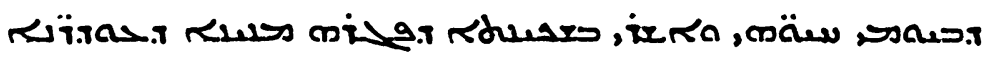
لیla

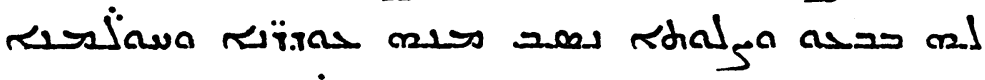

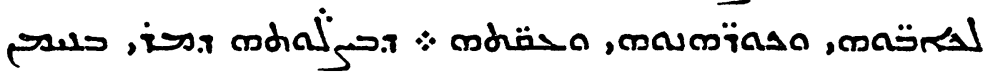

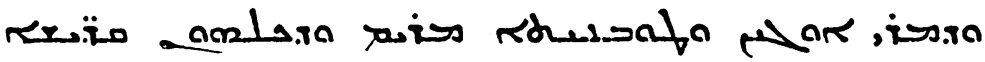

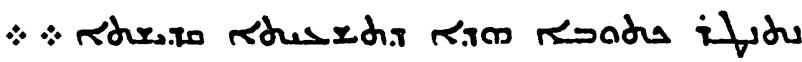

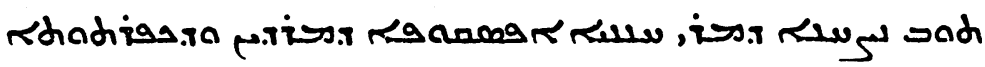
s.

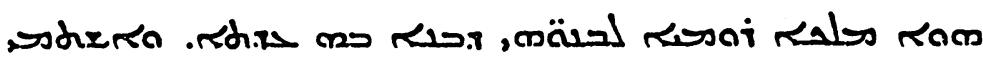

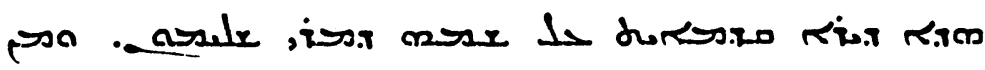

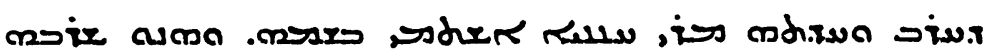

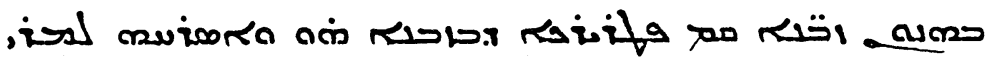

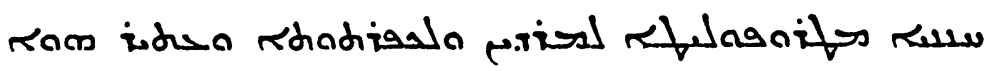
ده 


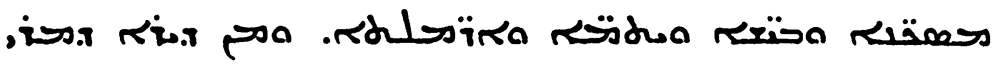

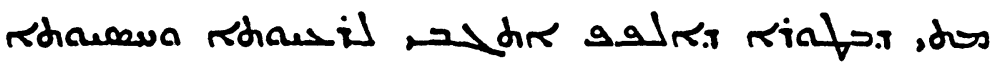

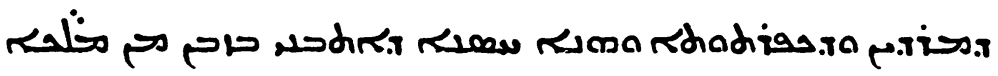
,

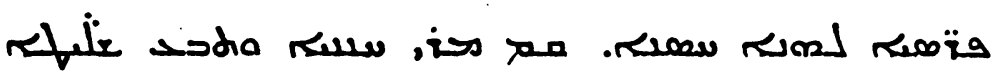

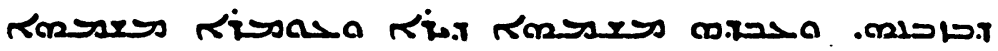

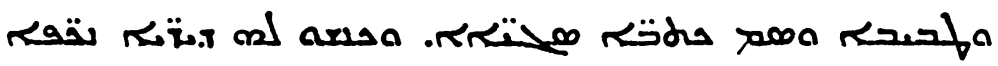

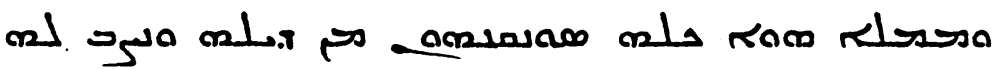
لحمدنr sis

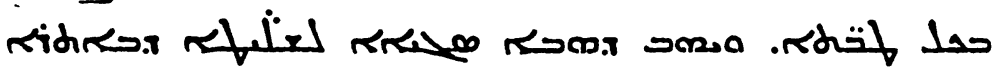

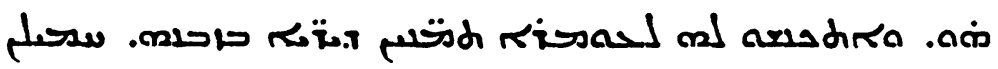

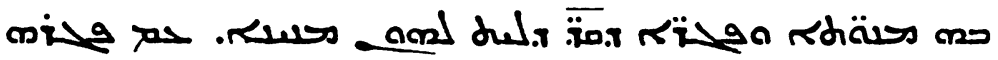

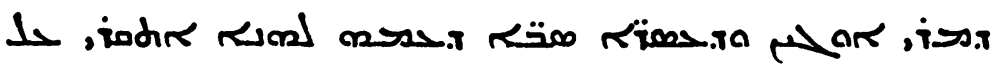

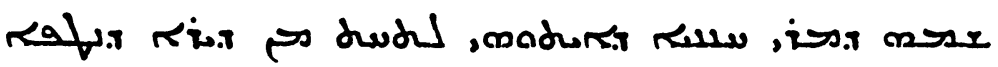
תמש

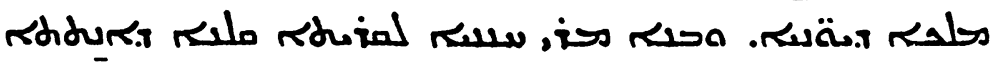

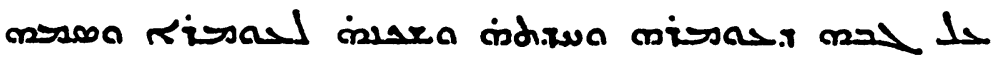

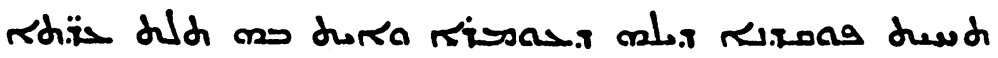

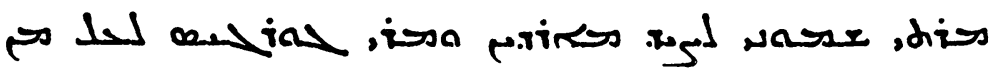

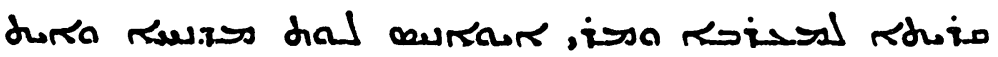

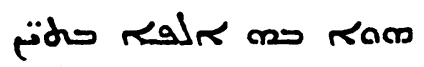

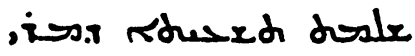

$$
\text { עسגבות }
$$


Après la lacune de $B$ allant de $A$ page 84 ligne I jusque p. 87 l: $7, B$ continue comme il suit ici. (Nous donnons $\mathrm{B}$ en entier à cause de la multiplicité des variantes insignifiantes.)

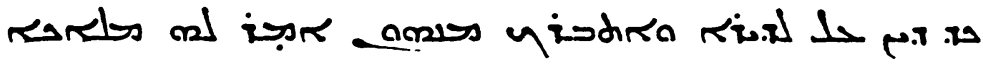

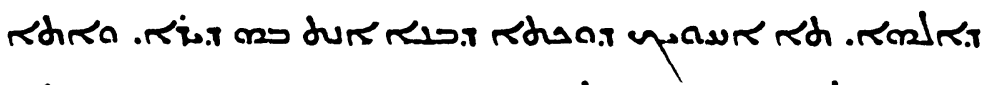

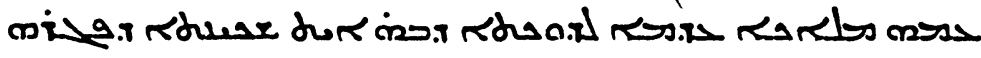
ת.

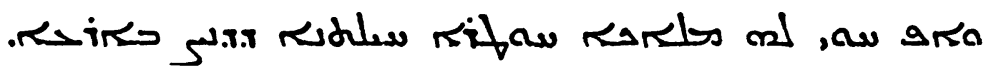

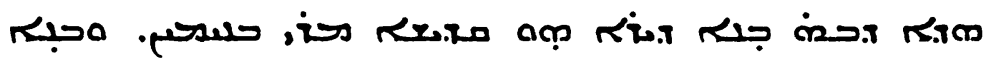

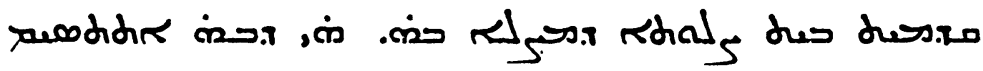

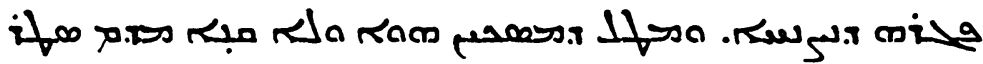

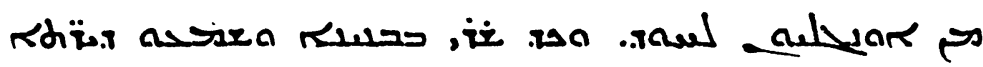

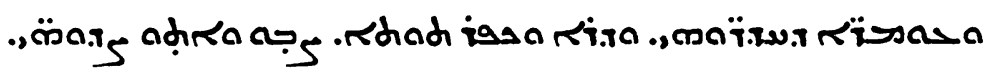
חאח

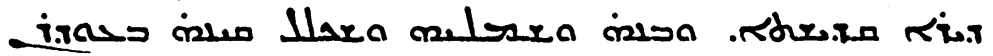

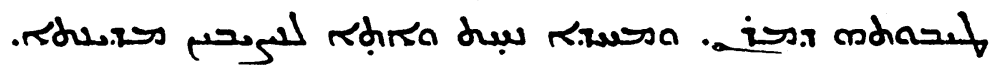

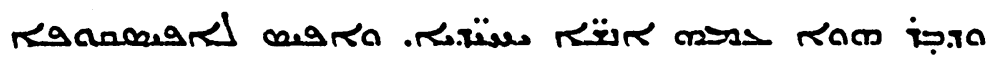

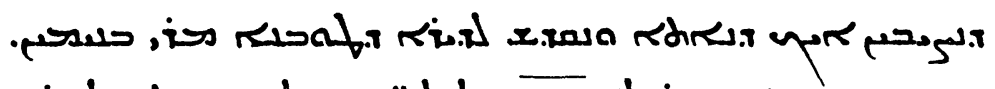

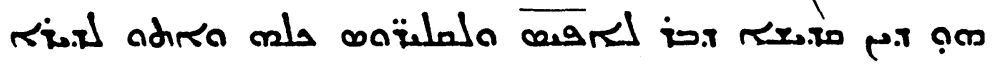
مסI.

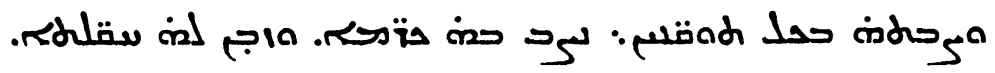

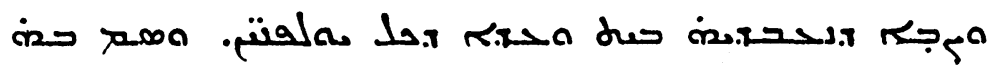
sلarr sevial

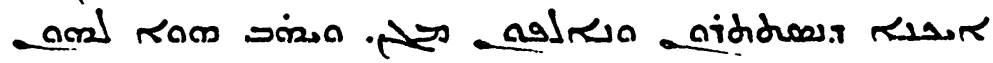




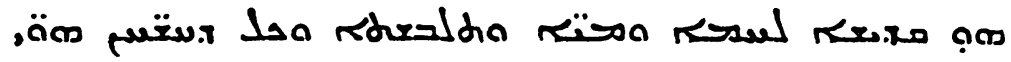

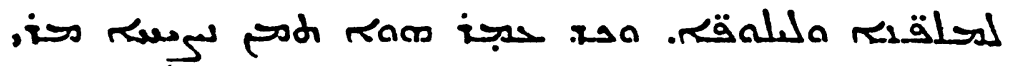

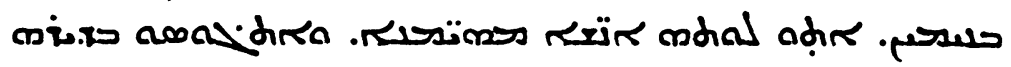

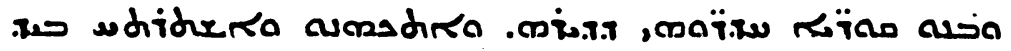
S

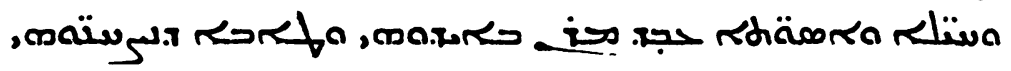

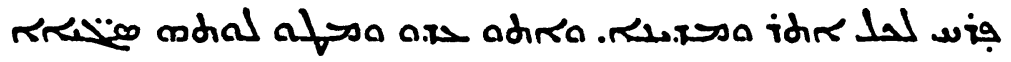

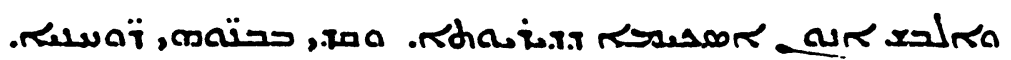

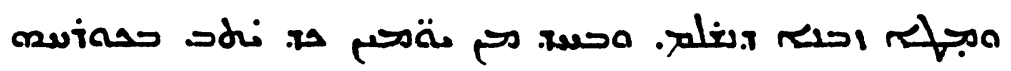

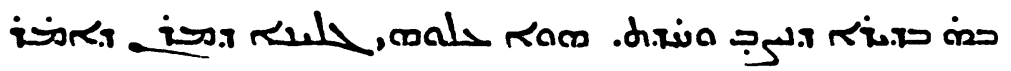

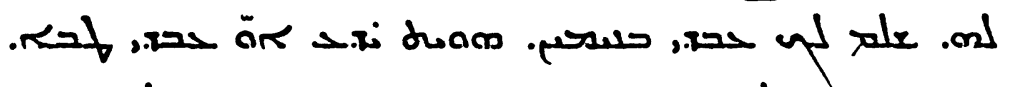

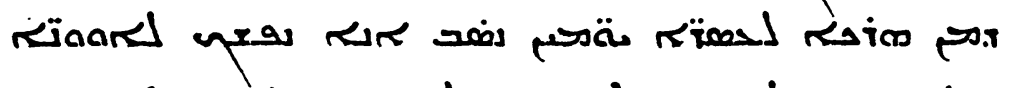
ז.

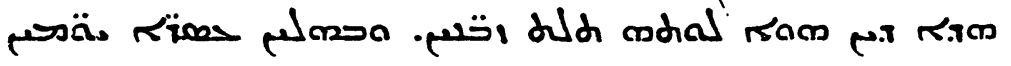

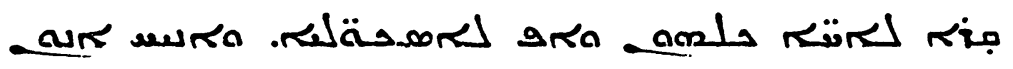
sدbror

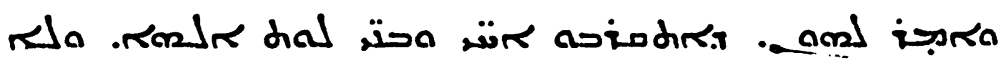
arash

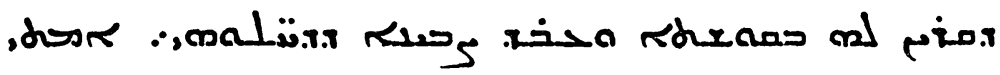
ل

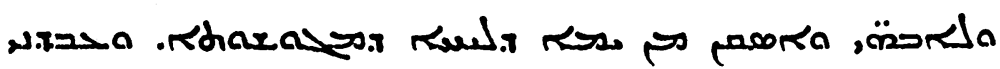

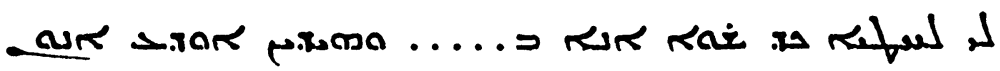

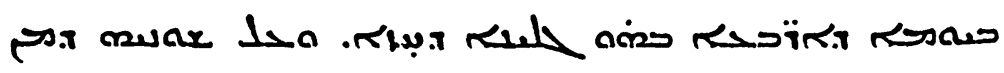

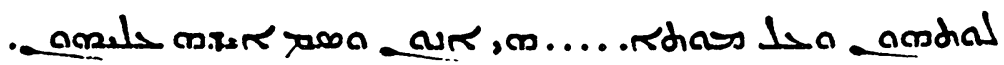




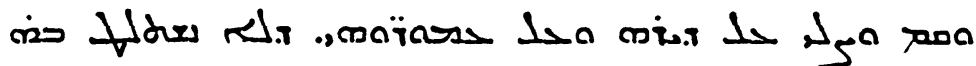

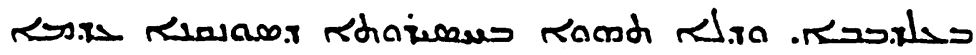

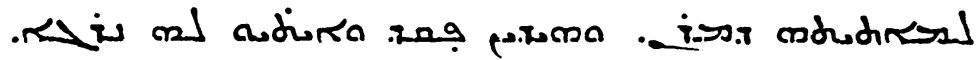

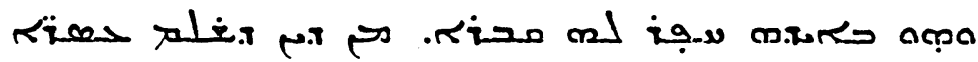

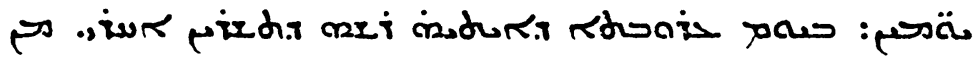

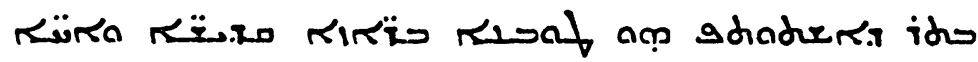

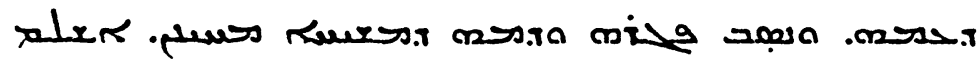

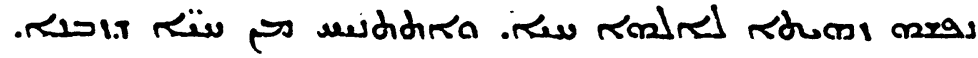

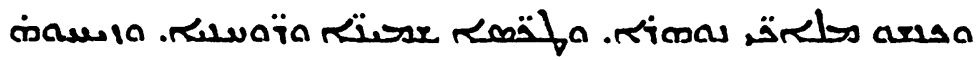

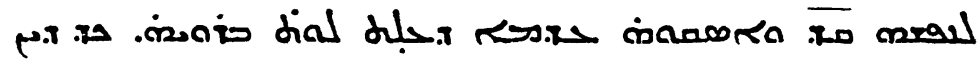

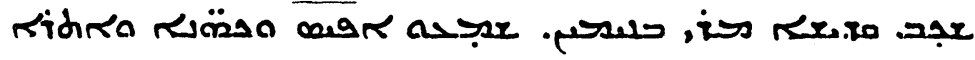

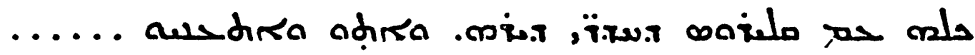

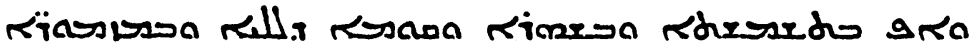

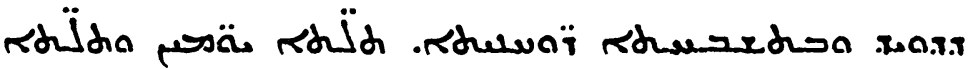

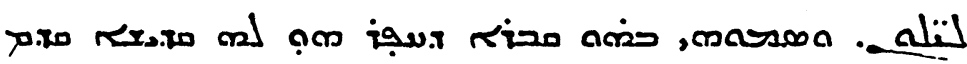

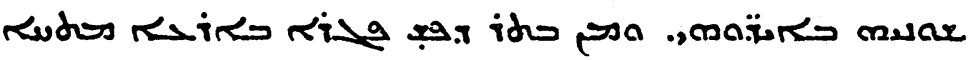
ז. vais

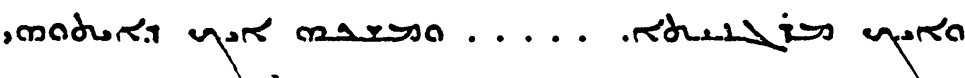

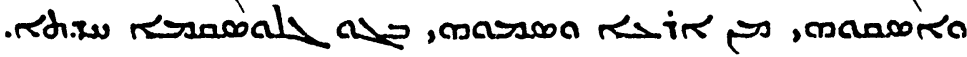

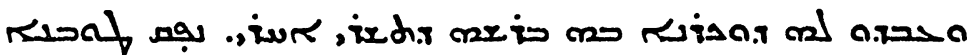

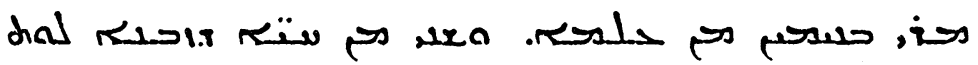

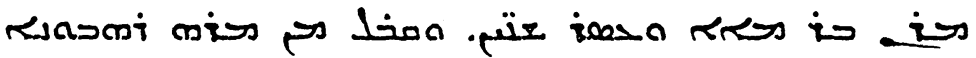
x 


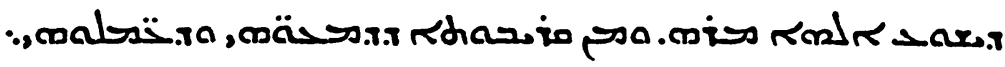
هل تُمله

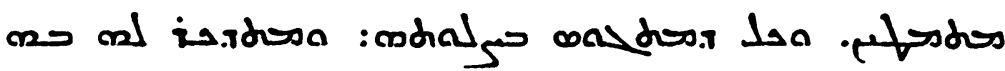

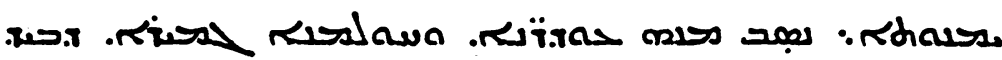

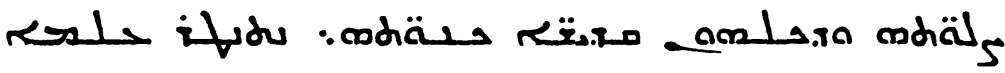

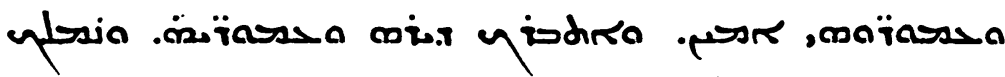

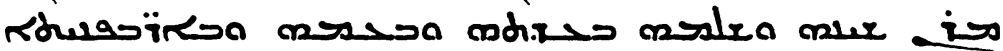

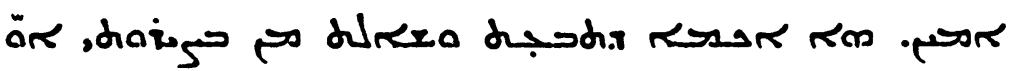

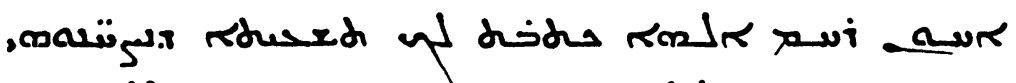

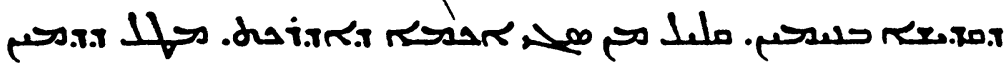

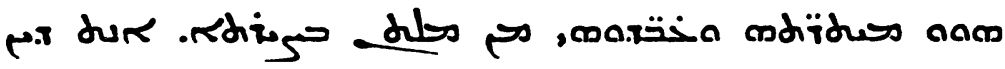

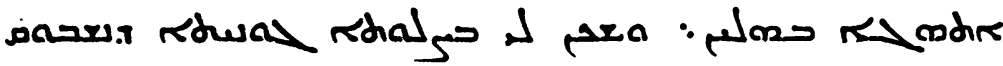

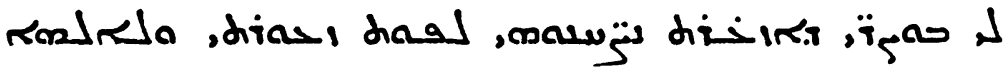

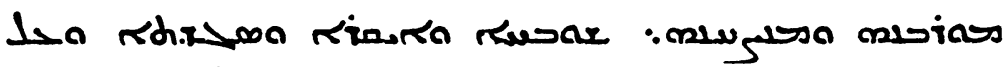

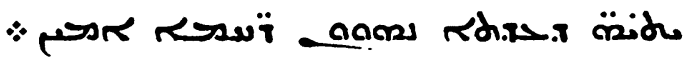

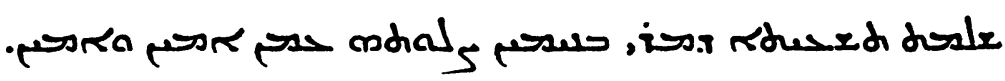
r. 